\title{
Quality over quantity: on workflow and model space exploration of 3D inversion of MT data
}

\author{
K. Robertson ${ }^{1,2^{*}}$ (D) S. Thiel ${ }^{1,2}$ (1) and N. Meqbel ${ }^{3,4}$ (i)
}

\begin{abstract}
3D inversions of magnetotelluric data are now almost standard, with computational power now allowing an inversion to be performed in a matter of days (or hours) rather than weeks. However, when compared to 2D inversions, these are still very computationally demanding. As a result, 3D inversions are generally not subjected to as rigorous testing as a $1 \mathrm{D}$ or $2 \mathrm{D}$ inversion would be, which has implications when these models are used for geological interpretation. In this study, we explore the parameter space for inversion of continent-scale datasets. The generalisations made regarding the effects of each parameter should also be scalable to smaller surveys and will enable MT practitioners to optimise their results. We have performed testing on a subset of the South Australian component of the eventual Australia-wide AusLAMP (Australian Lithospheric Architecture Magnetotelluric Project). The subset was inverted with different parameters, model setup and data subsets. Specifically, results from testing of the model covariance, the resistivity of the prior model, the inclusion of 'known' information into the prior model, the model cell size, the data components inverted for and the damping parameter $\lambda$ were all investigated. In our testing of the 3D inversion software, ModEM3DMT, we found that the resistivity of the starting/prior model had significant effect on the final model. Careful selection of initial $\lambda$ value can aid in reducing computational time whilst having a negligible effect on the resultant model, whilst large covariance values and model cell sizes enhanced conductive features at depth.
\end{abstract}

Keywords: Magnetotellurics, 3D inversion, AusLAMP, Electrical resistivity, ModEM3DMT

\section{Introduction}

The electrical resistivity structure of Earth is 3D. In a sedimentary basin, it often approximates to 1D. If geological structures have consistent strike direction across a region such as a long fault plane, maybe it approximates to $2 \mathrm{D}$ resistivity structure. More often than not, however, the geological structures are complex, and even if careful consideration of electromagnetic survey layouts is taken, e.g. measurements taken perpendicular to the strike direction, the data will inevitably be 3D in places. With the advance in 3D inversion codes and more readily

\footnotetext{
*Correspondence: Kate.Robertson2@sa.gov.au

${ }^{1}$ Department for Energy and Mining, Geological Survey of South Australia, Adelaide, Australia

Full list of author information is available at the end of the article
}

available high-performance computing facilities, magnetotelluric (MT) surveys are now commonly collected in arrays rather than transects and thus need to be inverted using a 3D code. Additionally, where transects are collected, it is now becoming more commonplace to invert using a 3D inversion code to allow for three-dimensionality of data (e.g. Robertson et al. (2016); Meqbel et al. (2016))

Ideally, ensembles of models from stochastic inversion methods will provide a variety of solutions that fall within the acceptable array of model parameters (Muñoz and Rath 2006). This is available in 1D (e.g. Cerv et al. 2007), or in 2D (e.g. Chen et al. 2012), but these types of probabilistic methods are difficult to realise in three dimensions due to the very expensive computational nature of this process when performing 
hundreds or even thousands of inversions. For now, deterministic methods are standard in 3D, and thus, it is vital that we have the highest level of assurance that the model we present is robust, or at the very least we know which features the model is sensitive to (i.e. required by the data).

This becomes critical when the models are used for quantitative geological interpretations such as calculating melt or fluid percentage, or determining the cause of a conductor (sulphides, graphite, hydrogen, etc.). To ensure interpretations are accurate, the range of resistivity values that could apply to a given feature should be considered in the interpretation, and an exploration of the model space is needed to determine these ranges. Various model resolution and sensitivity testing has occurred in 3D magnetotelluric inversions (see Miensopust 2017, for a comprehensive summary of these). When a preferred model is chosen, specific features are generally tested in a number of ways such as removing the feature in question and letting the inversion run for a few more iterations to see whether it returns or locking cells to certain values and seeing whether there is an effect on the model fit, etc. (e.g. Kelbert et al. 2012; Yang et al. 2015). Before one settles on a preferred model, there are a lot of parameters that can be tested, e.g. varying the model smoothing parameters, the starting resistivity, the inclusion of a priori information, the components inverted (e.g. full impedance tensor or offdiagonals only, the tipper, the phase tensor, etc.), the cell size, the method of error calculation and the error floors or the interstation sampling rate (e.g. inverting every second site). Testing all of these parameters is time-consuming and impractical in cases where significant computational time is not available, or model results are required quickly.

A thorough overview of how data errors, data components inverted and grid rotation affect 3D inversion has been conducted by Tietze and Ritter (2013), and a recent review of 3D modelling in practice by Miensopust (2017) exists, along with an investigation into some ModEM3DMT parameters (Slezak et al. 2019); however, as of yet, an in-depth overview of the many other modelling parameters that affect the resultant model is not available, and some of these will be investigated throughout this manuscript, specific to the 3D inversion code, ModEM3DMT.

We present recommendations for modelling MT arrays using the inversion code ModEM3DMT (Egbert and Kelbert 2012; Kelbert et al. 2014), tested by performing many 3D inversions on AusLAMP data in northeast South Australia (Fig. 1). AusLAMP is the Australian Lithospheric Architecture Magnetotelluric Project, which aims to provide a $3 \mathrm{D}$ image of the electrical resistivity distribution of the crust and mantle beneath the Australian continent by acquiring long-period MT data at approximately 2800 sites across Australia at half-degree intervals (approximately $55 \mathrm{~km}$ ).
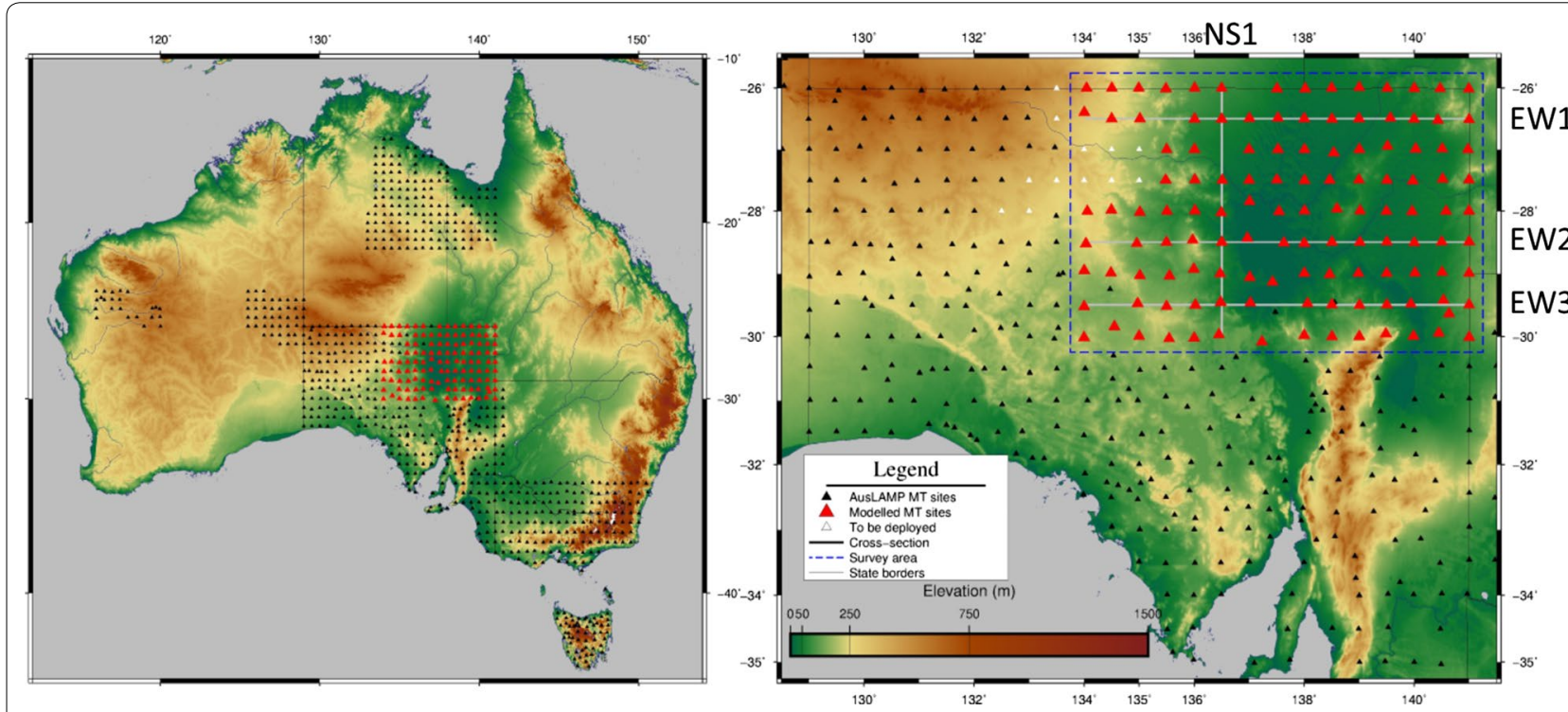

Fig. 1 Left: AusLAMP long-period MT site deployed locations (black) across Australia. Sites used in this study are red. Right: AusLAMP long-period MT site deployed locations (black) and intended locations (white) over topography in South Australia. The red sites were used in the 3D modelling presented in this study. The survey area is outlined in blue. The grey lines show the locations of the cross sections used for visualising modelling results in later figures 
We aim to explore the model space, showing how varying selected modelling parameters and starting models affect the resultant model. We intend to provide direction on what may significantly affect the resultant model, and in doing so, this may give the reader an indication of which types of inversion configuration they can run to get the best resultant model for their data.

The MT dataset used in these tests is comprised of 123 long-period MT sites, across a $\sim 55 \mathrm{~km}$ spaced array covering an area of 350 (east-west) $\times 700$ (north-south) $\mathrm{km}$. Various testing was done including varying the initial damping value, a trade-off between data misfit and model regularisation $(\lambda)$, incorporating a highly conductive mantle beneath the $410 \mathrm{~km}$ and $660 \mathrm{~km}$ seismic discontinuities, altering the resistivity of the half-space (that includes conductive ocean), varying the model covariance, the model horizontal cell size and lastly the data components (impedance tensor and tipper) included in the inversion.

\section{Methods}

The long-period MT data used for this investigation were mostly collected from November 2016 to July 2017 in the northeast AusLAMP acquisition project, but also utilised two rows of AusLAMP data south of the northeast project region, which have previously been modelled (Robertson et al. 2016). The total number of sites was 123 (including 120 AusLAMP sites and three legacy sites), and the data were processed using BIRRP (Chave and Thomson 2004), remote referenced using simultaneously recording sites (Gamble et al. 1979). The sites recorded five components (Ex, Ey, Bx, By and Bz) using non-polarisable $\mathrm{Pb}-\mathrm{PbCl}$ electrodes and a fluxgate magnetometer with a sampling rate of $10 \mathrm{~Hz}$. Each site was left out for about 3 weeks and provided frequency-domain data over a period range of approximately $5-20,000 \mathrm{~s}$, with $10-16,000 \mathrm{~s}$ (23 periods) inverted for the impedance tensor and 10-9000 s (21 periods) used for the tipper (as the planar wave approximation fundamental to the magnetotelluric theory starts to break down at longer periods). All inversions presented were performed using the parallelised nonlinear conjugate gradient (NLCG) algorithm of ModEM3DMT (Egbert and Kelbert 2012; Kelbert et al. 2014), which aims to minimise the penalty function:

$$
\begin{aligned}
\Psi(m, d)= & (d-f(m))^{\mathrm{T}} C_{\mathrm{d}}^{-1}(d-f(m)) \\
& +\lambda\left(m-m_{\text {prior }}\right)^{T} C_{\mathrm{m}}^{-1}\left(m-m_{\text {prior }}\right)
\end{aligned}
$$

where $d$ is the observed data, $m$ the conductivity model, $f(m)$ the forward response of $m, C_{d}$ the data covariance, $m_{\text {prior }}$ the prior model, $C_{m}$ the model covariance and $\lambda$ the damping parameter, a trade-off parameter between data misfit and model structure. The code penalises smoothed deviations from a prior model, with a spatial covariance where small-scale features are more heavily penalised. The inversions were run on Raijin, a high-performance computational facility of the National Computational Infrastructure (NCI), in parallel across 48 cores. (Optimal number of cores is equal to twice the number of periods inverted +1 .) The model parameters that are generally unchanged (unless specified) whilst other parameters were investigated are as follows. Where the $X$ direction is $\mathrm{N}-\mathrm{S}$, and the $Y$ direction is $\mathrm{E}-\mathrm{W}$, the number of cells is $54(X) \times 104(Y)$, plus 15 padding cells (with a size increase factor of 1.3) in each direction, totalling $96 \times 132$ cells. The horizontal cell size is $7500 \times 7500 \mathrm{~m}$, resulting in a model size of $2899(X) \times 3275(Y) \mathrm{km}$, with only $350(X) \times 700(Y) \mathrm{km}$ of that as the survey area (the area which includes MT sites). The vertical $(Z)$ thickness begins at $25 \mathrm{~m}$ with 75 layers increasing by a factor of 1.135 to a total depth of $2467 \mathrm{~km}$. The survey area is mostly covered by deep sedimentary basins, usually associated with low static shift in the Australian environment. Most sites are unaffected by static shift, and it is intended that the very thin near-surface layers will account for those sites that do exhibit static shift effects caused by near-surface inhomogeneities of the data. The ocean is incorporated (bathymetry from https://maps.ngdc.noaa. gov/) with a resistivity of $0.3 \Omega \mathrm{m}$ along with underlying sediments with resistivity of $0.3 \Omega \mathrm{m}$ linearly increasing to the background resistivity for $2 \mathrm{~km}$ beneath the base of the ocean. The resistivity of the sediment layer is not fixed. From previous experience of modelling AusLAMP data, we chose to start exploring the model domain by using a smoothing parameter (covariance value) of 0.4 in $X, Y$ and $Z$ directions. The covariance is applied on a cell basis rather than a distance basis, where larger values favour larger scale variations and/or smaller contrasts. Error floors for all testing are 3\% of $\sqrt{|Z x y * Z y x|}$ for the off-diagonal components, $Z x y$ and $Z y x, 7 \%$ of $\sqrt{|Z x y * Z y x|}$ for $Z x x$ and $Z y y$ and 0.01 for the respective tipper components, $T z x$ and $T z y$. The starting $\lambda$ is 10 .

\section{Results and discussion}

For each test, the preferred parameter was chosen based on a number of criteria; firstly, whether the overall RMS is within $10 \%$ of the lowest overall RMS from the inversions included in that test. Inversions could subsequently be excluded based on visual appearance, such as a very speckled model or a distinct lack of model heterogeneity with depth. Lastly, a parameter is introduced as a measure of the variance of the RMS both between the data subsets used in the inversion (RMS of $Z$ and $T$, $\mathrm{RMS}_{\text {all }}$; RMS of $Z$ only, $\mathrm{RMS}_{Z}$; RMS of $T$ only, $\mathrm{RMS}_{T}$ ) and the variance of the RMS with period, represented by the RMS per decade (RMS divided into period range of 10-100, 
$100-1000$ and $1000-10,000 \mathrm{~s}$ for each component $(Z+T$, $Z, T)$ ), with a desire to minimise the variance of these values so that the most equal weighting of the data components, and the data across the entire period range, can be found. The RMS variance parameter RMS $\mathrm{var}_{\mathrm{va}}$ is defined as follows:

$$
\begin{aligned}
\mathrm{RMS}_{\mathrm{var}}= & 0.25 *\left(\mathrm{RMS}_{\mathrm{OAvar}}+\mathrm{RMS}_{10-100 \mathrm{var}}\right. \\
& \left.+\mathrm{RMS}_{100-1000 \mathrm{var}}+\mathrm{RMS}_{1000-10,000 \mathrm{var}}\right)
\end{aligned}
$$

where

$$
\mathrm{RMS}_{\mathrm{OAvar}}=100 *\left|\left(\mathrm{RMS}_{Z}-\mathrm{RMS}_{T}\right)\right| / \mathrm{RMS}_{\text {all }}
$$

and $\mathrm{RMS}_{x-y \mathrm{var}}$ are calculated the same as $\mathrm{RMS}_{\mathrm{OAvar}}$ except for over a limited bandwidth where $x$ and $y$ are the minimum and maximum period of the decade. Whilst these criteria were used to select our preferred parameter, we did not always use the preferred parameter in further testing, usually to minimise computational time [referred to herein in KSU, where $1 \mathrm{KSU}$ is one thousand service units (or $1000 \mathrm{~h}$ ) on supercomputer Raijin] for subsequent tests.

\section{Initial damping parameter- $\lambda$}

A user-defined variable in the inversion process is the initial damping parameter, $\lambda$. As $\lambda$ decreases throughout the inversion, the model progressively fits the data better with smaller scale structures and larger conductivity contrasts. The user can define an initial $(\lambda)$ value along with a $\lambda$ exit value (default $1.0 \mathrm{e}-8$ ) that when reached, causes the inversion to exit. This is usually the cause of an inversion exit unless the target RMS is reached (default 1.05). When the RMS decrease per iteration is less than a certain value (default $1.0 \mathrm{e}-3$ ), then $\lambda$ is decreased by a user input divisor (default 10), and this process is repeated until the $\lambda$ exit value is reached. This process ensures that the orthogonality of the search direction vector is maintained and allows the algorithm to escape from a local minimum (Meqbel et al. 2016). An initial damping parameter of 1,10, 100 and 1000 was tested (with $\lambda$ exit value and divisor kept as default), with the results outlined in Figs. 2 and 3. The starting resistivity for these tests was $100 \Omega \mathrm{m}$. We have given the RMS as the resultant overall RMS and as the RMS per decade. The RMS per decade is the RMS for a period range of $10-100 \mathrm{~s}$, $100-1000 \mathrm{~s}$, and 1000 and $10,000 \mathrm{~s}$, to give an indication of how the models are fitting the shortest, intermediate and longest periods. Generally speaking, 10-100 s incorporates periods where each station cannot fully sense the adjacent station (resulting in the 'speckled' appearance of the shallow domain in some models); $100-1000 \mathrm{~s}$ is roughly crustal depths; and 1000-10000 approximates

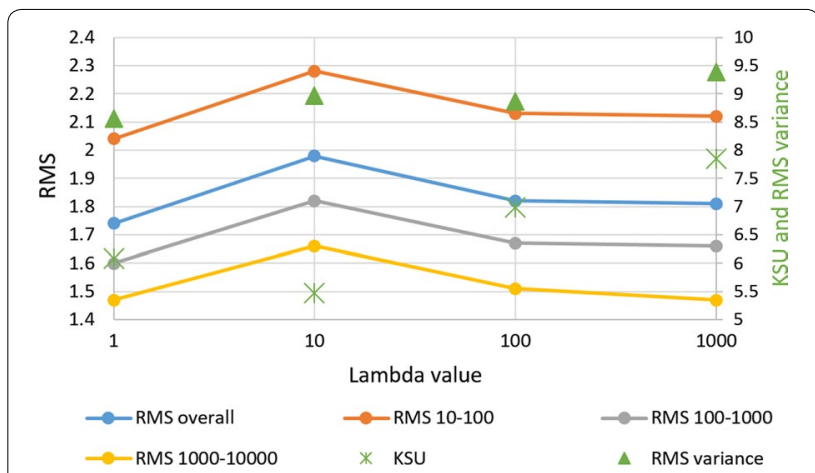

Fig. 2 Summary of overall RMS, and RMS per period decade, for models testing the initial $\lambda$ for 1000,100, 10 and 1. The number of KSU used for each inversion and the RMS $\mathrm{Var}_{\text {are }}$ also displayed with values on the right vertical axis

mantle depths and controls the deep features in the model. The RMS and RMS per decade for these models are similar (Fig. 2) with $\lambda$ of 10 slightly higher (overall RMS 14\% larger than the minimum RMS). Visually, the inversions look similar. The ideal starting $\lambda$ was deemed to be 1 , obtaining the lowest RMS of 1.74 after 169 iterations, having the lowest $\mathrm{RMS}_{\mathrm{var}}$ indicating the best distribution of model fit across the period range and individual data components. Additionally, the inversion converged in 49 less iterations than that of $\lambda 1000$. However, a $\lambda$ of 10 took only 152 iterations with an RMS of 1.98 and was used for further testing, significantly reducing computational time in further tests.

\section{Known resistivities}

We test the hypothesis that the incorporation of known resistivities into the prior model returns a better model than using a half-space and/or may reduce the number of iterations required. By known, we mean information that is reasonably and consistently inferred from other geophysical datasets. To do this, we used a half-space (no ocean) with resistivity of $100 \Omega \mathrm{m}$ and covariance of 0.4 to compare to models with one individual known feature added at a time. The known features are as follows: bathymetry (with ocean resistivity of $0.3 \Omega \mathrm{m}$ ), $10 \Omega \mathrm{m}$ resistivity beneath the $410 \mathrm{~km}$ seismic discontinuity and $1 \Omega \mathrm{m}$ resistivity beneath the $660 \mathrm{~km}$ seismic discontinuity. The inclusion of these features is described in more detail in the following sections, and the inversions are summarised in Table 1 and plotted in Figs. 4 and 5.

\section{Bathymetry}

It is commonplace in $3 \mathrm{D}$ magnetotelluric inversion to include bathymetry in the prior model. Sea water has a very low resistivity of about $0.3 \Omega \mathrm{m}$ and thus generally is in stark contrast with the much more resistive 


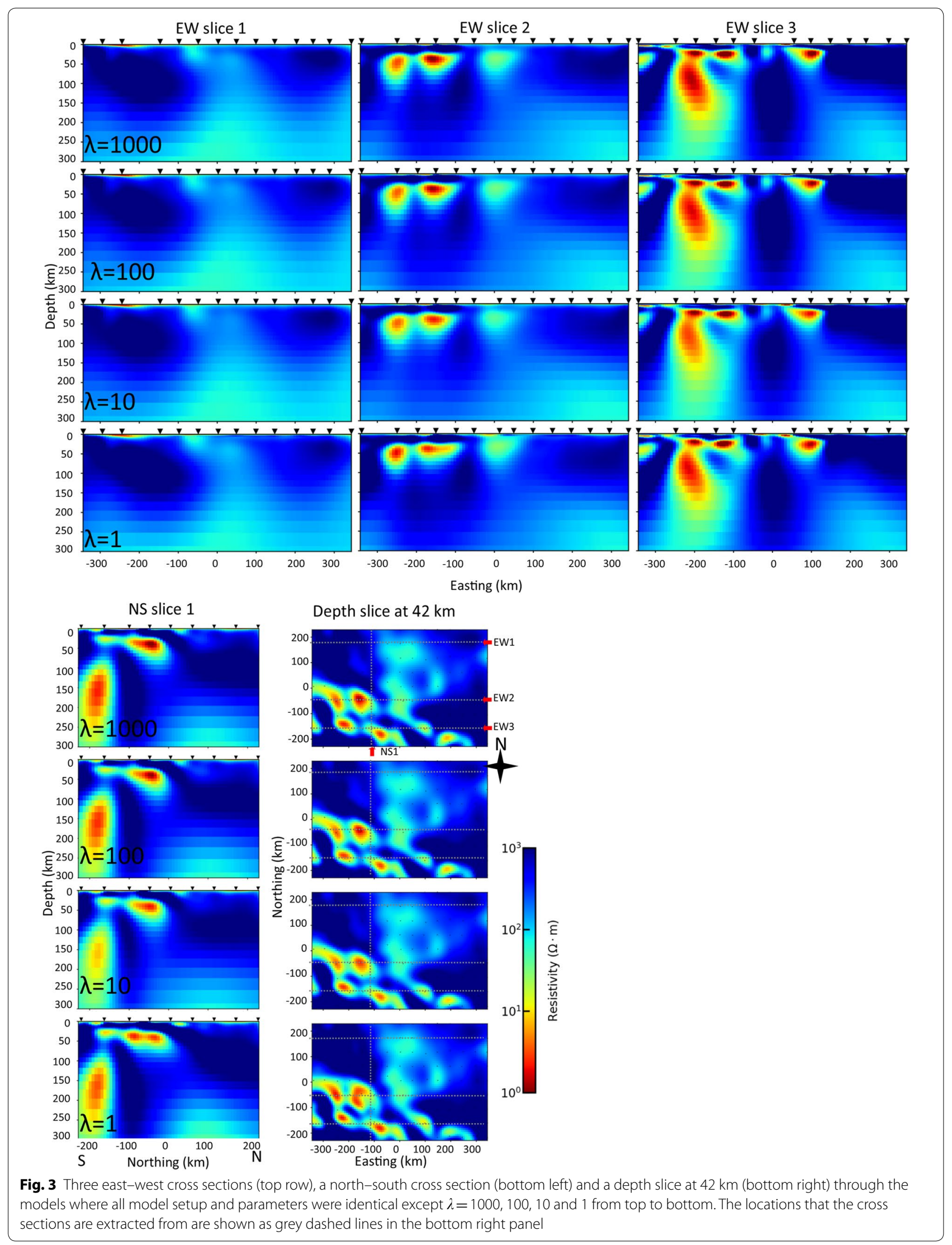


Table 1 Information that is included in the prior model for four different inversions

\begin{tabular}{|c|c|c|c|c|c|c|c|}
\hline Bath and seds & $410 \mathrm{~km}$ & $660 \mathrm{~km}$ & Overall RMS & 10-100s RMS & 100-1000s RMS & $1000-10,000$ s RMS & $\begin{array}{l}\text { No. } \\
\text { of iterations }\end{array}$ \\
\hline- & - & - & 1.82 & 2.11 & 1.66 & 1.54 & 162 \\
\hline$\checkmark$ & - & - & 1.98 & 2.28 & 1.82 & 1.66 & 152 \\
\hline$\checkmark$ & $\checkmark$ & - & 1.81 & 2.11 & 1.66 & 1.51 & 182 \\
\hline$\checkmark$ & $\checkmark$ & $\checkmark$ & 1.71 & 2.02 & 1.55 & 1.43 & 181 \\
\hline
\end{tabular}

Bath and seds includes sea water with resistivity of $0.3 \Omega \mathrm{m}$ and linearly increasing resistivity to a depth $2 \mathrm{~km}$ beneath the ocean bottom where it reaches the halfspace resistivity. The $410 \mathrm{~km}$ prior model has resistivity decreased to $10 \Omega \mathrm{m}$ beneath the $410 \mathrm{~km}$ seismic discontinuity. The $660 \mathrm{~km}$ prior model has resistivity of $10 \Omega \mathrm{m}$ beneath $410 \mathrm{~km}$ and $1 \Omega \mathrm{m}$ beneath $660 \mathrm{~km}$. Each model had a starting RMS of 47.5
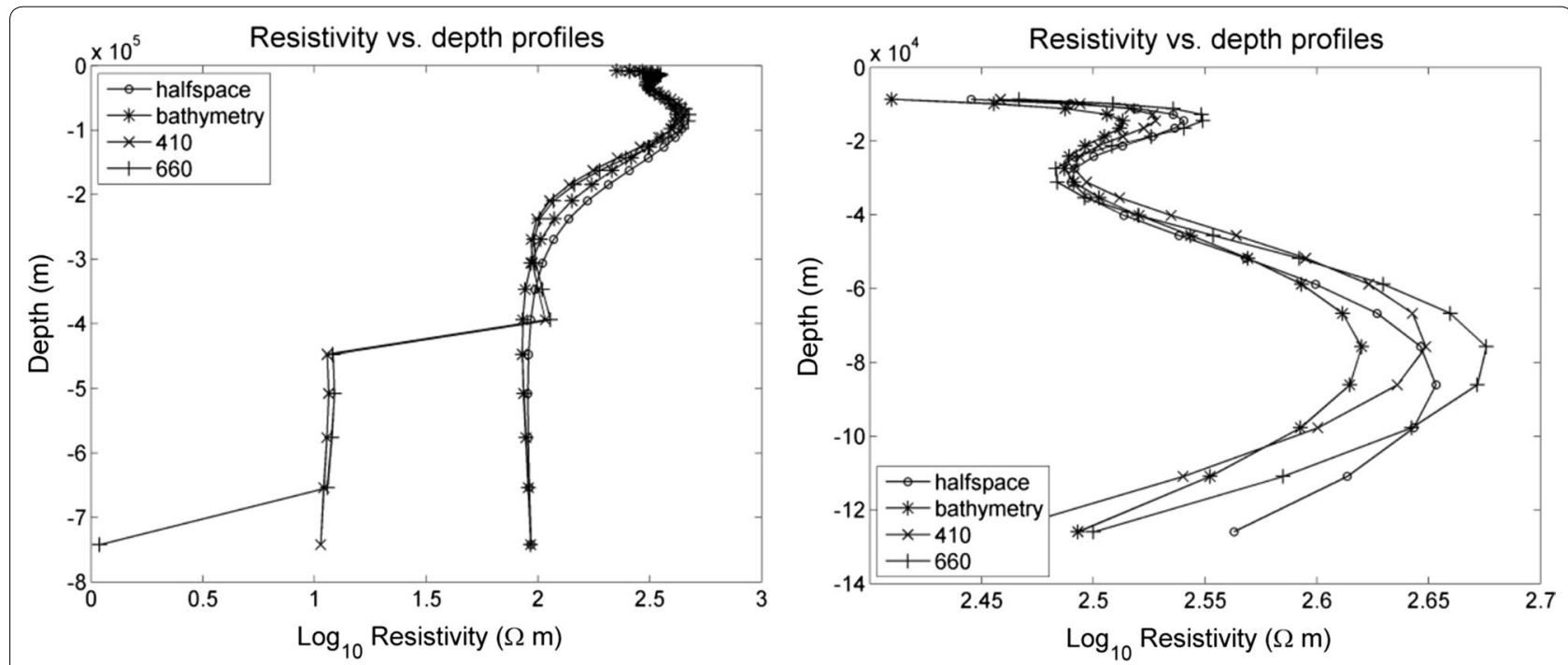

Fig. 4 The averaged resistivity values taken from the inversions with different resistivities for the various prior models for depths of 10 to $750 \mathrm{~km}$ (left) and 10 to $140 \mathrm{~km}$ (right)

lithosphere. The existence of sea water around the survey area also severely affects observed MT responses, known as the geomagnetic coast effect (Parkinson and Jones 1979). The sea has a substantial influence on observed MT data particularly when the separation distance from the coast is smaller than the skin depth of the frequency of interest. The skin depth of a typical long-period MT survey (such as this study) can readily reach up to a few hundred kilometres, so ocean effects can be noticeable over quite some distance. However, the closest point of the survey area to the ocean is about $200 \mathrm{~km}$ and the inclusion of bathymetry had little effect on the resultant inversion with the RMS remaining similar (9\% increase from 1.82 to 1.98 ), and the inversions visually are almost identical. The inversion converged with 10 less iterations than the half-space starting model inversion.

\section{Mantle discontinuities 410 and $660 \mathrm{~km}$}

Seismic models around the world reveal an abrupt increase in seismic velocity at a depth of $410 \mathrm{~km}-$ a result of the transition from olivine to wadsleyite (Shearer and Flanagan 1999). This transition additionally shows a decrease in resistivity to $10 \Omega \mathrm{m}$ (Huang et al. 2005; Yoshino et al. 2008). At $660 \mathrm{~km}$ another seismic discontinuity exists, expected as a result of a phase transition from ringwoodite to bridgmanite and periclase (Ito and Takahashi 1989; Ishii et al. 2018). Both of these transitions are associated with decreases in resistivity. To test whether it is useful to incorporate this information into the prior model, we have set the resistivity beneath 410 $\mathrm{km}$ to $10 \Omega \mathrm{m}$ and then with $1 \Omega \mathrm{m}$ beneath $660 \mathrm{~km}$ depth (Constable 2015; Xu et al. 2000). These resistivities were not fixed in the model.

\section{Summary of prior models}

As additional prior information is incorporated in this study, there is a small improvement on the overall model fit (with the exception of the bathymetry only model), as represented by the RMS. The cross sections and depth slices taken through the model (Figs. 4 and 


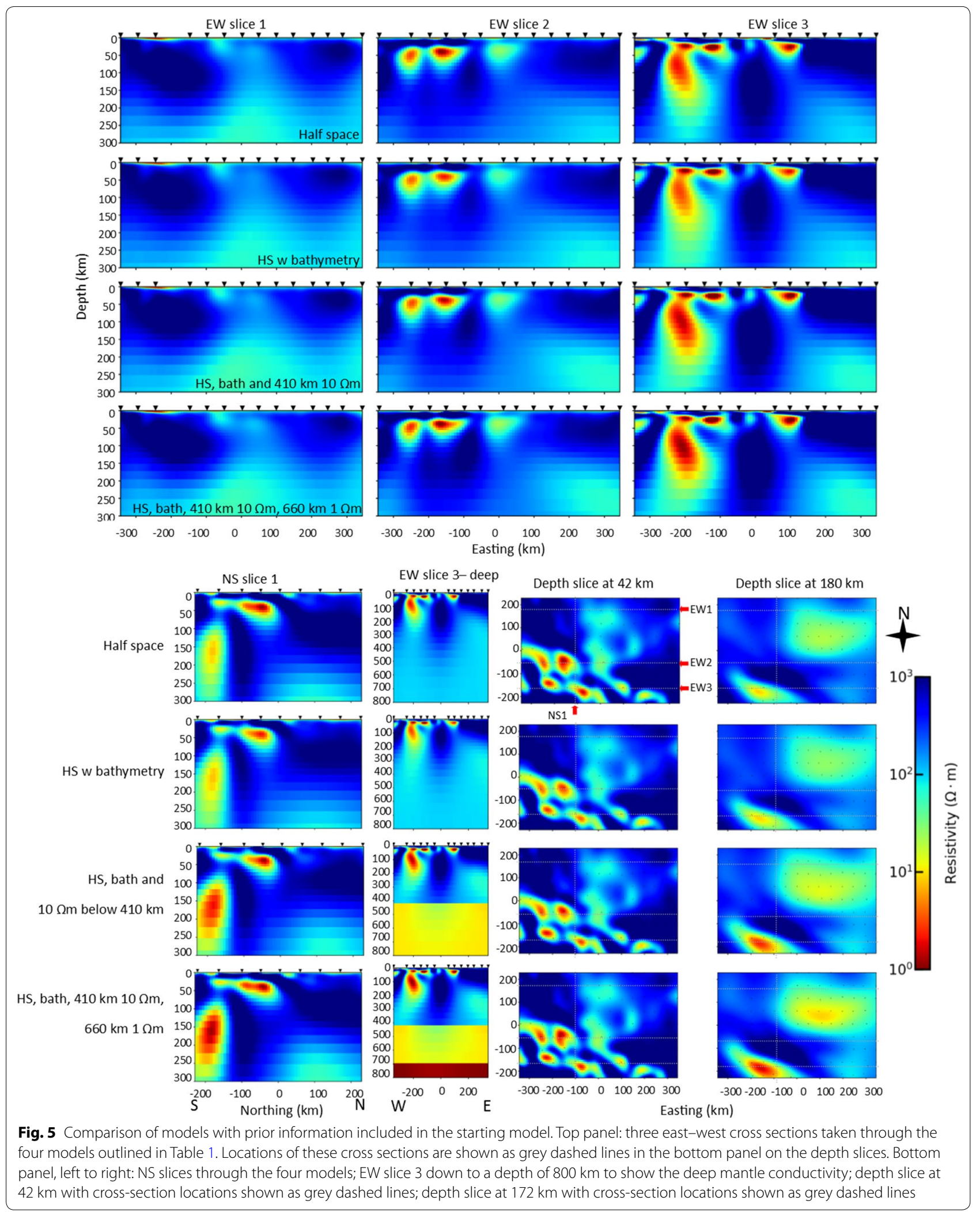


5) are reasonably similar. Visually, there is little difference between the half-space model and the model with bathymetry and ocean bottom sediments, although the overall RMS increased from 1.82 to 1.98 , but taking 10 less iterations. The impact of including this information is expected to be more significant if the ocean was closer to the survey area, and/or if the survey had a larger aperture. Including a conductive mantle beneath $410 \mathrm{~km}$ depth converged after 182 iterations, 30 more iterations than when only bathymetry information are included. The RMS decreased with this extra information but only minutely from 1.98 to 1.81 . Once the even more conductive mantle beneath $660 \mathrm{~km}$ was added, the RMS decreased slightly again, from 1.81 to 1.71 , taking 29 more iterations than the bathymetry only inversion. These two models that incorporated enhanced conductivities beneath $410 \mathrm{~km}$ are less resistive at depth, particularly in the southwest of the model region which can be seen in the NS slice 1 and in the averaged resistivity-depth curves (Figs. 4 and 5) The variation in RMS between all of these models is marginal, and all but one of the models (the one with bathymetry only) have an overall RMS within $10 \%$ of the model with the lowest overall RMS. Using the selection criteria outlined earlier, it is deduced that the inclusion of no prior information is the preferred model, with an RMS within $10 \%$ of the smallest overall RMS for those tested, and with the smallest $\mathrm{RMS}_{\mathrm{var}}$. However, given that we expect that the inclusion of the ocean would be much more important in a survey region closer to the ocean, the second preferred model may be better, which include all of the prior information that we tested, bathymetry and reducing the prior conductivity to $10 \Omega \mathrm{m}$ beneath $410 \mathrm{~km}$ and $1 \Omega \mathrm{m}$ beneath $660 \mathrm{~km}$. The model that we used for further testing was neither of these models-we instead used the bathymetry only model due to the much less computational time required for this inversion.

\section{Starting resistivity in prior model}

ModEM3DMT allows the user to input a starting model and a prior model. The prior model is a compulsory input, and by default if no starting model is given, then the model starts from the prior model. In regions of the model poorly constrained by the data (e.g. in areas outside of the survey area or at depths exceeding MT signal penetration), the resistivities usually revert to the resistivity of the prior model. No independent starting model was included in any of the tests; thus, the start model is identical to the prior model. A variety of resistivities were tested for the prior/starting model (half-space plus ocean where ocean is locked at resistivity of $0.3 \Omega \mathrm{m}$, with bathymetry taken from https:// maps.ngdc.noaa.gov/). The land part of the model was varied to resistivity values that were evenly spaced on a $\log$ scale, 10, 31.6, 100, 316 and $1000 \Omega \mathrm{m}(1,1.5,2,2.5$ and 3 on log scale). In addition, the average apparent resistivity of all data points across all sites and all periods was calculated to be $69 \Omega \mathrm{m}$, and this was used also as a prior model. Depth slices (Fig. 9) and cross sections (Fig. 10) show key features of the models.

It is difficult to determine the best resistivity for the prior model as most of the inversions fit the data similarly well (for example, the difference in overall RMS between the 10 and $69 \Omega \mathrm{m}$ prior models is only 0.18 , a $10 \%$ decrease from 1.84 to 1.66 ), with the exception of $1000 \Omega \mathrm{m}$ prior model and less so the $316 \Omega \mathrm{m}$ and $100 \Omega \mathrm{m}$, which show a poorer model fit both by overall RMS and RMS per decade (Figs. 6 and 7). The misfit reduction should also be considered in this case (starting RMS-final RMS/starting RMS). The largest percentage decrease in misfit occurs for the models with the highest starting resistivity (Fig. 6). The largest range in RMS between models occurs in the 10-100 s range with RMS varying between 2.45 for $1000 \Omega \mathrm{m}$ and 1.85 for $10 \Omega \mathrm{m}$. This is likely a result of the lack of sensitivity at shallow depths in between $55 \mathrm{~km}$ spaced stations. The skin depth for periods longer than $100 \mathrm{~s}$ is roughly similar or larger than the interstation spacing, and this reduces the dependency on the starting half-space. In areas of known sedimentation, a low starting resistivity near the surface where there is little to no sensitivity between stations may serve to reduce the spottiness near the surface, with the resistivity staying close to the starting resistivity, and close to the resistivity values achieved beneath the sites where there is sensitivity. Sediments within our survey region are known to have a resistivity within the range of $6 \Omega \mathrm{m}$ in top 1.5 $\mathrm{km}$, and $25 \mathrm{~m}$ in the $2 \mathrm{~km}$ beneath from broadband MT

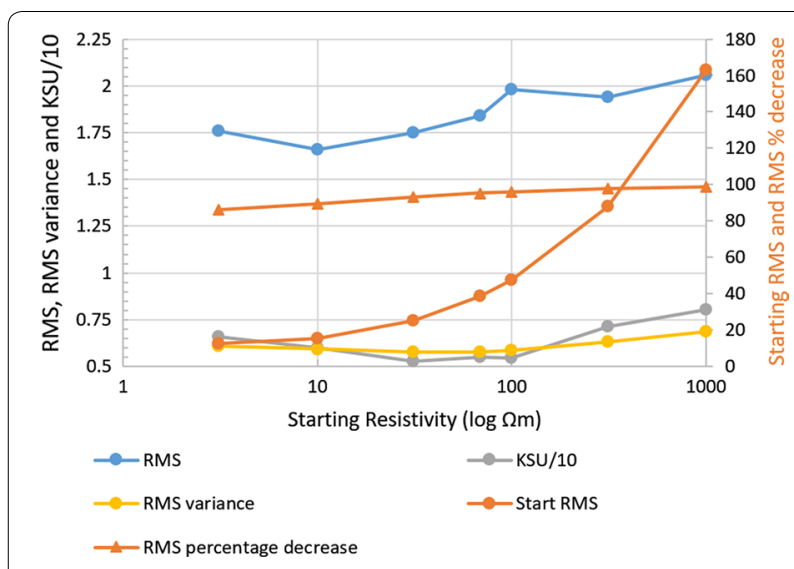

Fig. 6 The RMS per decade (10-100, 100-1000 and 1000-10,000 s) for seven different inversions with differing starting half-spaces, 3, 10, $31,69,100,316$ and $1000 \Omega \mathrm{m}$ 


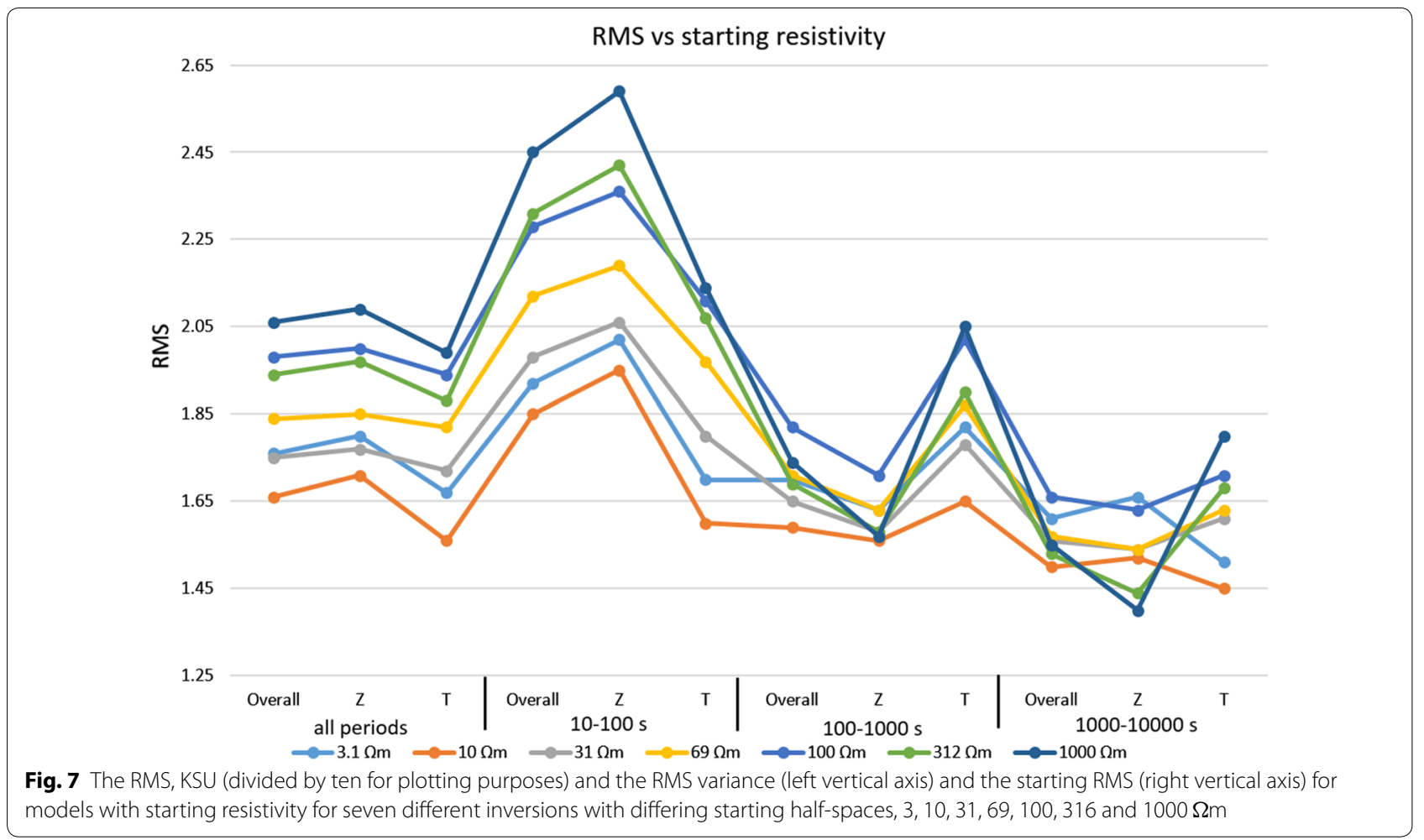

surveys and well resistivity logs (Didana et al. 2017). This explains the best RMS in the 10-100 s bandwidth for a $10 \Omega \mathrm{m}$ starting resistivity which sits between 6 and $25 \Omega \mathrm{m}$.

The influence of the prior model on the final converged model was found to be significant, with a general trend being that the more conductive the prior/starting model, the more conductive the final model. For each converged model, the resistivities were averaged for each depth (excluding model padding cells) and are visualised in Fig. 8. By a depth of $400 \mathrm{~km}$, the average resistivity is very similar to the prior model resistivity which indicates

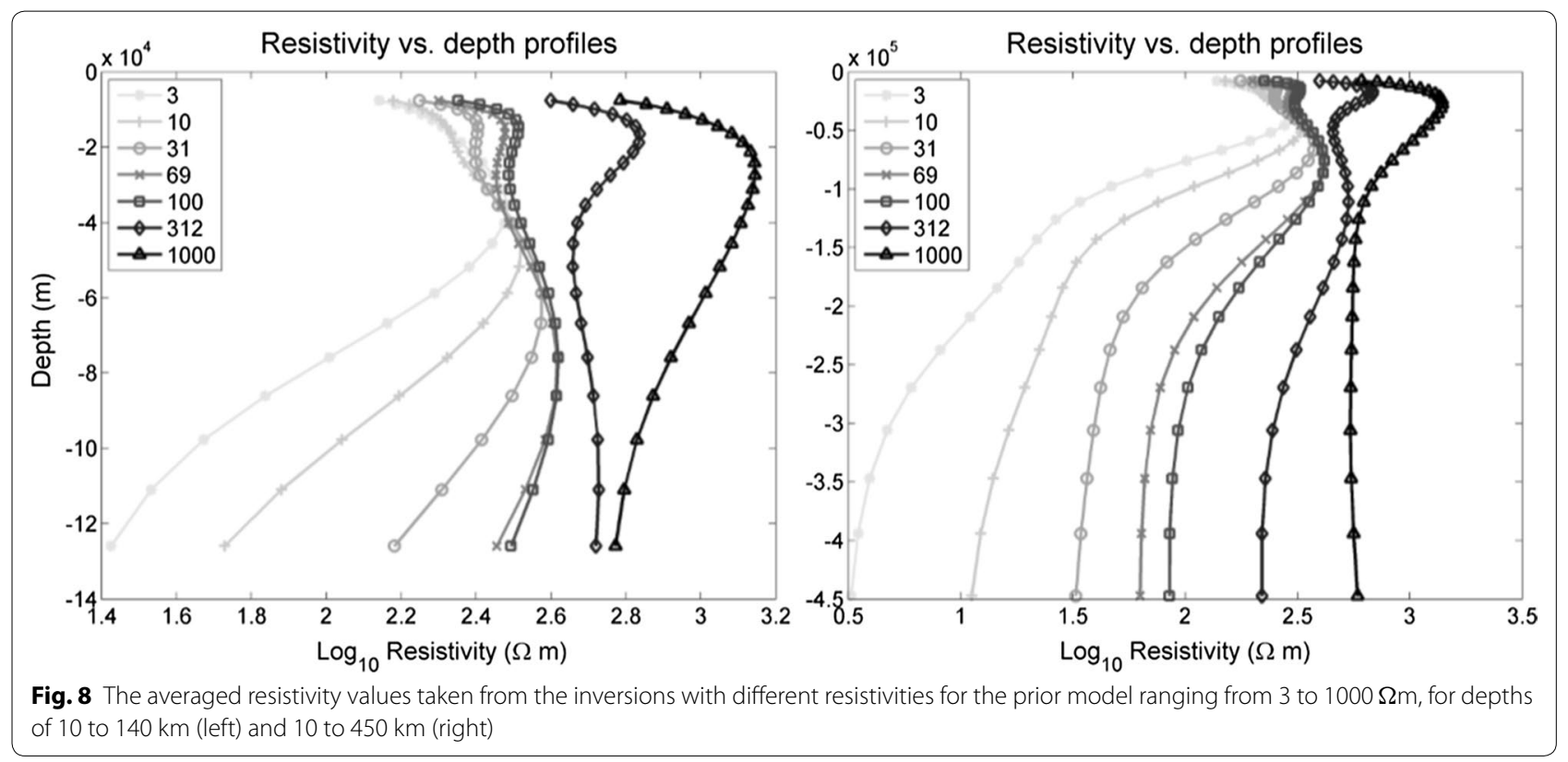


a lack of sensitivity at these depths. Similarly at shallow depths, the effect of skin depth and station spacing can be seen. The variation in averaged resistivity for the different models reflects 'residual' or leftover starting resistivity between stations that cannot be constrained by the coarse station spacing $(55 \mathrm{~km})$ and by the short data periods (shortest period $\sim 0 \mathrm{~s}$ ).

The averaged resistivity of the most conductive model (3 $\Omega \mathrm{m}$ prior) and the most resistive model $(1000 \Omega \mathrm{m}$ prior) is most similar in lower crustal to shallow upper mantle depths (Moho depth $\sim 36 \mathrm{~km}$ in most of the model region; Kennett et al. 2011) where sensitivity peaks. The smallest spread occurs around $40 \mathrm{~km}$ depth where the resistivity varies by $0.733 \log \Omega \mathrm{m}$ between these models (from 3.19log $\Omega \mathrm{m}$ for the $1000 \Omega \mathrm{m}$ prior to $2.46 \log \Omega \mathrm{m}$ for the $3 \Omega \mathrm{m}$ prior). However, if we restrict the analysis by eliminating the 316 and $1000 \Omega \mathrm{m}$ (due to a significantly poorer fit of these models), the range decreases to just $0.06 \log \Omega \mathrm{m}$ (from $2.52 \log \Omega \mathrm{m}$ for the $100 \Omega \mathrm{m}$ prior to $2.46 \log \Omega \mathrm{m}$ for the $3 \Omega \mathrm{m}$ prior). At $10 \mathrm{~km}$ depth, the range (again excluding 316 and $1000 \Omega \mathrm{m}$ ) is $0.12 \log \Omega \mathrm{m}$ (from $2.45 \log \Omega \mathrm{m}$ for the $100 \Omega \mathrm{m}$ prior to $2.33 \log \Omega \mathrm{m}$ for the $3 \Omega \mathrm{m}$ prior), and by $100 \mathrm{~km}$, the range is $0.92 \log \Omega \mathrm{m}$ (from $2.59 \log \Omega \mathrm{m}$ for the $100 \Omega \mathrm{m}$ prior to $1.67 \log \Omega \mathrm{m}$ for the $3 \Omega \mathrm{m}$ prior). These results highlight the importance of choosing a reasonable prior model as the absolute values of the resistivity of the converged model is very dependent on the starting model. Whilst these results do not give a definitive answer of which of these models is best, we have confidence that 316 and $1000 \Omega \mathrm{m}$ are too resistive as indicated by the substantially higher initial and final RMS values (Figs. 6 and 7). Averaging the apparent resistivity for every site and every period as we did with the $69 \Omega \mathrm{m}$ model similar to the method of Meqbel et al. (2014) seems like a suitable approach for a ballpark resistivity for a prior model half-space with the RMS of 1.84 for this model $10 \%$ higher than the best achieved RMS of 1.66. In regions where sedimentation is known to occur, a lower starting resistivity (using the averaged resistivity across only the shortest periods) may serve to minimise the 'speckling' in shallow inversion slices; however, we note that in our tests these low starting resistivities introduce large heterogeneities in deep model slices which should be treated with caution (e.g. $172 \mathrm{~km}$ depth slice for 3 and $10 \Omega \mathrm{m}$ models in Fig. 9).

To gain further insight from this test, the average of the best four models (each had a final RMS within $15 \%$ of the lowest RMS achieved for inversions within this test; 3, 10,31 and $69 \Omega \mathrm{m}$ ) was used to calculate the average and the standard deviation of the models. The average model is not very useful information given that it is dependent on the starting resistivities that are used (e.g. if we had only run 10,31 and $100 \Omega \mathrm{m}$ models, then the average resistivity model would be a lot more conductive than when we include the higher resistivity prior models of 316 and $1000 \Omega \mathrm{m}$ ). However, the standard deviation provides useful information on the uncertainty of features and a snapshot of the standard deviation at depths of 42 and $172 \mathrm{~km}$ is shown in Fig. 11.

Some of the main features of the model are labelled in the depth slices of Fig. 9 in the $3 \Omega \mathrm{m}$ prior model. C1a is evident in all of the models (Figs. 9 and 10), whereas C3 is only distinct in the 3 and $10 \Omega \mathrm{m}$ prior models. For models with 3 and $10 \Omega \mathrm{m}$ prior resistivities, C1a is further north than the other models, and conductor $\mathrm{C} 1 \mathrm{~b}$ appears to the southwest. For higher starting resistivity models, the $\mathrm{C} 1 \mathrm{a}$ feature is further south and the $\mathrm{C} 1 \mathrm{~b}$ is no longer required in the model. The southwest corner of the model is associated with the highest uncertainties at 42 $\mathrm{km}$ depth (Fig. 11). The location of the C1a and/or C1b is uncertain. Conductor $\mathrm{C} 2$ is west-northwest oriented and occurs on the edge of a transition from resistive in the southwest to the more conductive northeast of the model for inversions with priors of $31 \Omega \mathrm{m}$ or less. This feature is not present in all models and as such the standard deviation here is very high in the $172 \mathrm{~km}$ depth slice. C3 is very conductive and situated in the mantle in the southeast of the model region. It only appears in those models with priors of 10 and $3 \Omega \mathrm{m}$ or less. This region also has very high uncertainties (Fig. 11).

For subsequent inversions, we choose to use the $31 \Omega \mathrm{m}$ model for the rest of the investigations; it has the lowest $\mathrm{RMS}_{\mathrm{var}}$ of those models that have an overall RMS within $10 \%$ of the minimum overall RMS of all tests. Visually, this inversion was also preferred as the extremely conductive $\mathrm{C} 2$ and $\mathrm{C} 3$ features in the mantle in the 3 and $10 \Omega \mathrm{m}$ prior model are less pronounced which is preferred given the high uncertainty of these features (Fig. 11). We used $31 \Omega \mathrm{m}$ for further testing given that it also takes the least number of iterations.

\section{Covariance}

The ModEM3DMT code penalises smoothed deviations from a prior model. The covariance controls the behaviour of the model norm, a higher covariance results in a smoother overall model with fewer small-scale and rough features which are more heavily penalised. The ModEM inversion routine has the ability to define how many times the covariance matrix is applied across the cells of the horizontal layers at the same model perturbation. For our tests, we use the value of 2, i.e. the covariance matrix is applied twice (with the exception of one test), which results in generally smoother gradients compared to applying it once. Many covariance values were tested within the possible range of values between 0 and 1 (default covariance is 0.3 ), where 


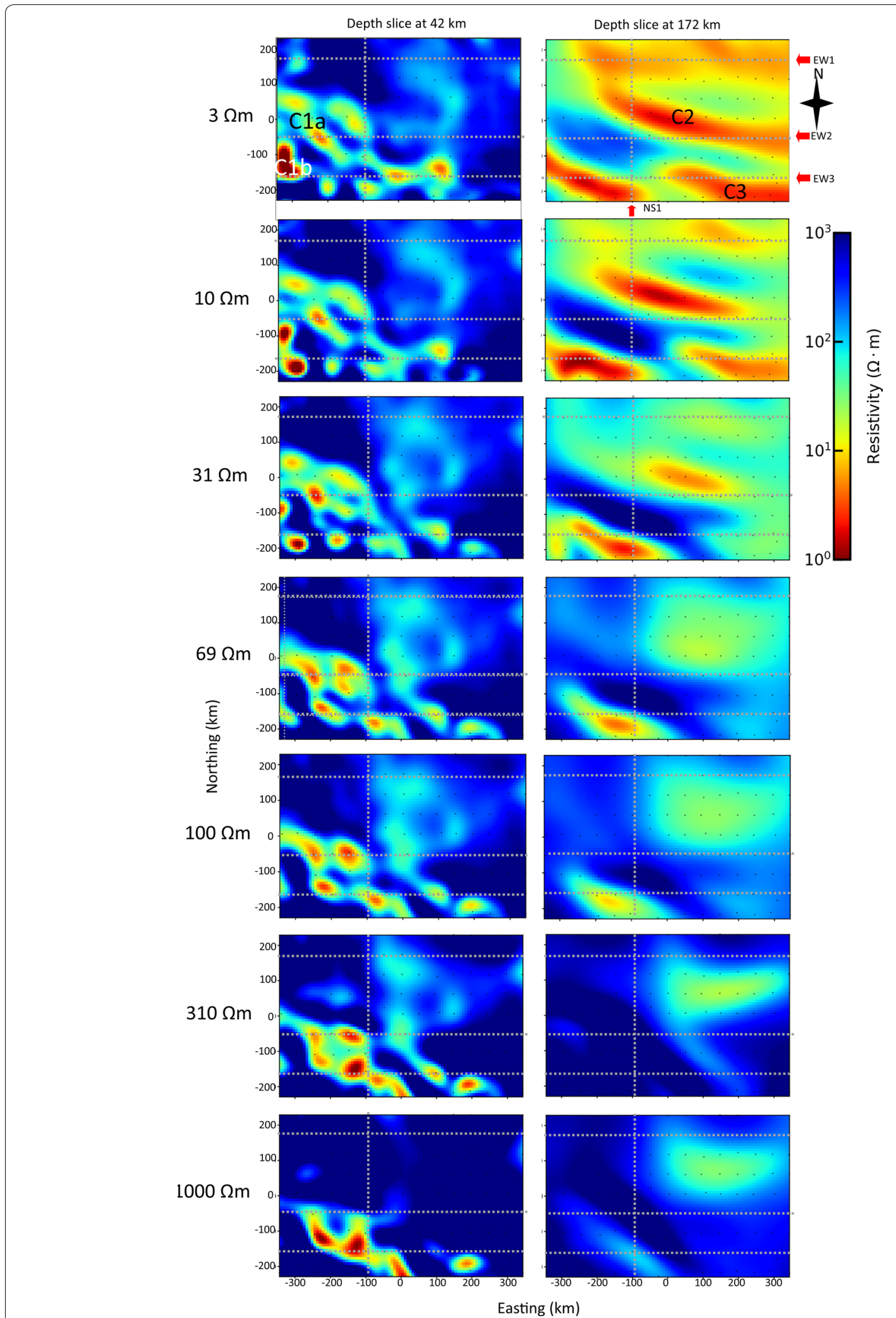

Fig. 9 Column 1: depth slice through inversions with 3, 10, 31, 69, 100, 312 and $1000 \Omega \mathrm{m}$ prior resistivity at a depth of $42 \mathrm{~km}$. Column 2: as column 1 but for a depth of $172 \mathrm{~km}$. The location of the sections from Fig. 10 is shown as grey dashed lines on the right-hand column 


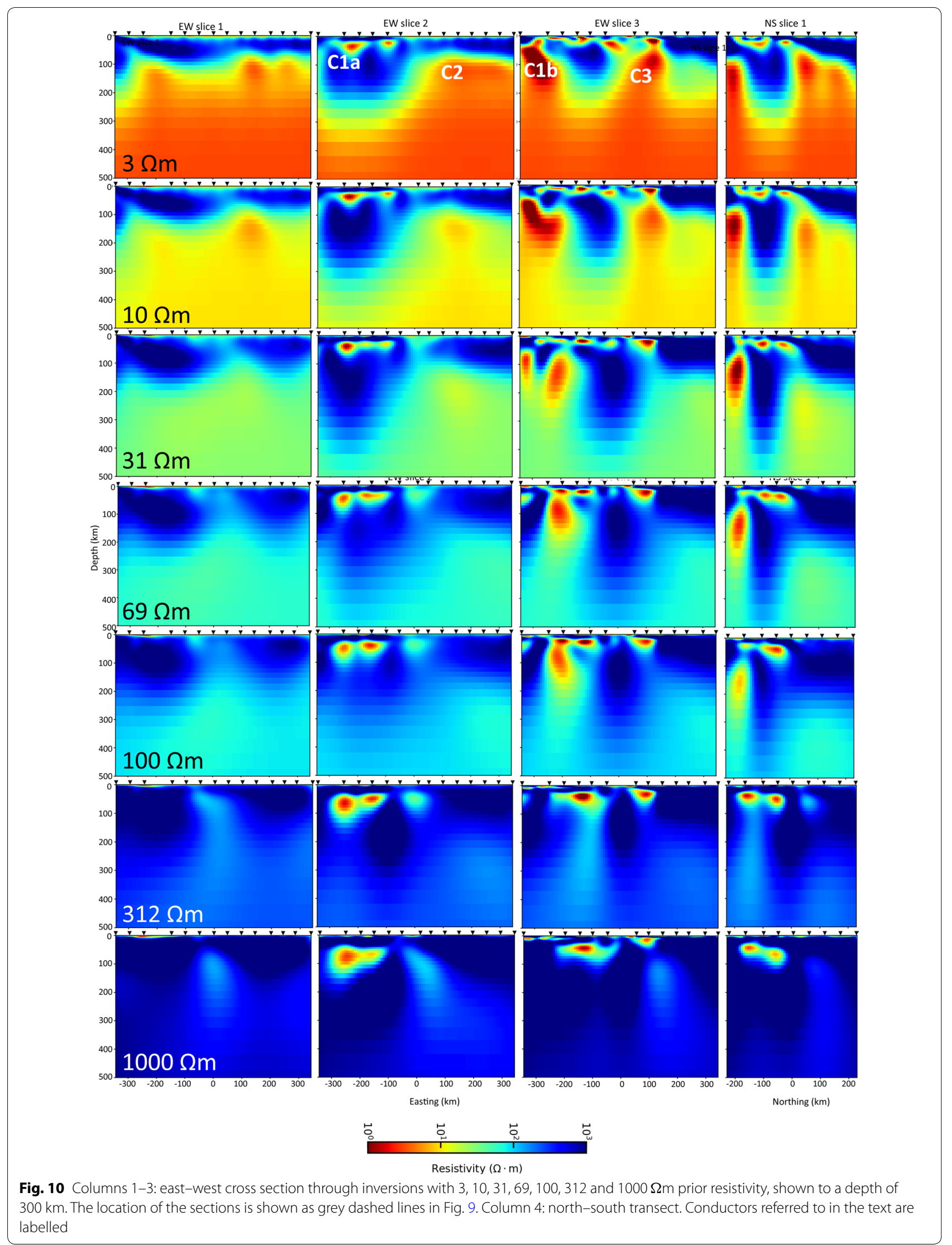




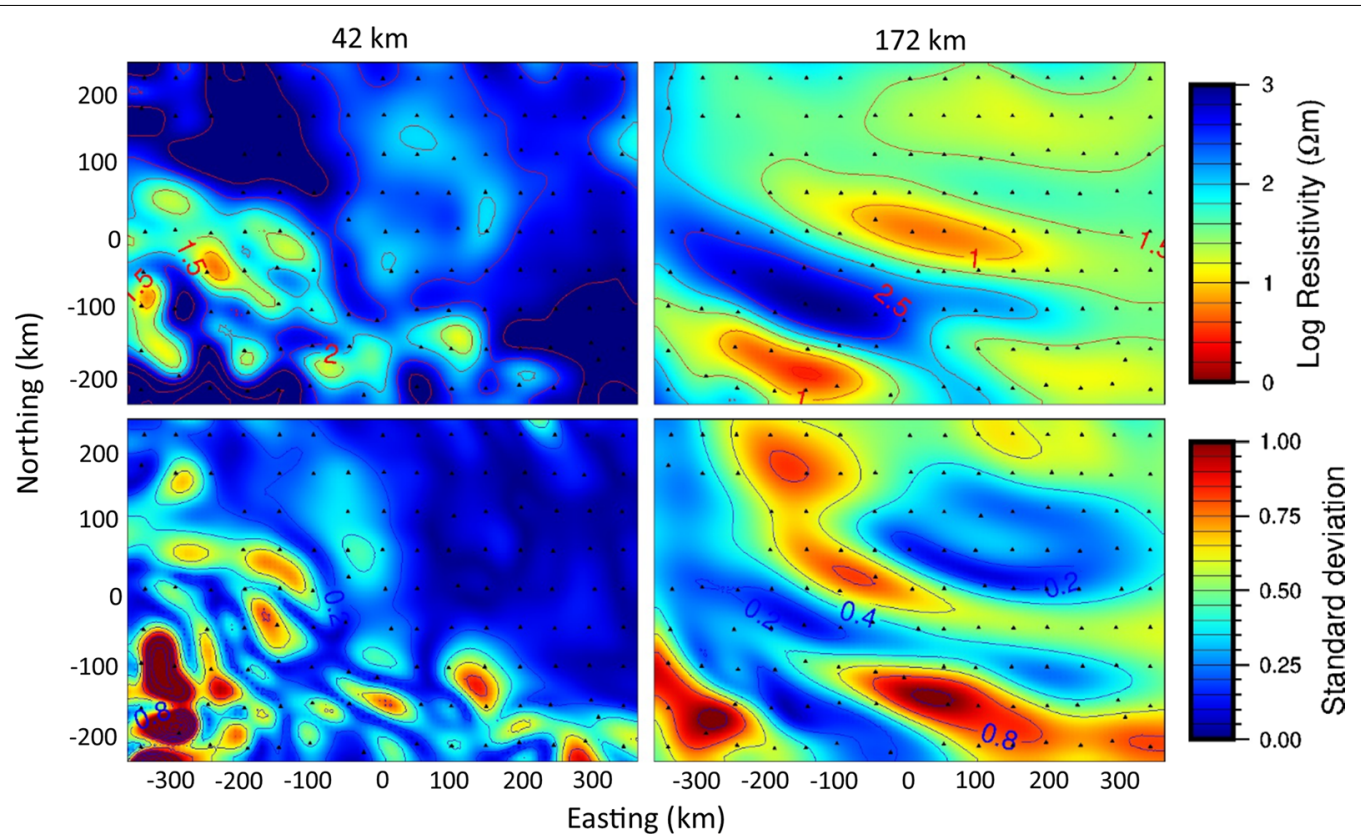

Fig. 11 Average and standard deviation of ModEM inversions with prior resistivities of 10, 31.6, 69, 100, 316 and $1000 \Omega \mathrm{m}$. Black triangles are locations of MT sites. A standard deviation of 0.2 at a certain point in the model means that $68 \%$ of the data lie within 0.2 log resistivity of the average value of that cell (averaged across all starting models). For example, average value at a point $=100 \Omega \mathrm{m}$ (or $2 \log \Omega \mathrm{m}$ ), St. Dev $=0.2 \mathrm{log} \Omega \mathrm{m}$, and then $68 \%$ of values lie within $\pm 0.2 \log \Omega \mathrm{m}$ or between 1.8 and $2.2 \mathrm{log} \Omega \mathrm{m}$ or between 65 and $160 \Omega \mathrm{m}$. The top row shows the average resistivity values (with $0.5 \Omega \mathrm{m}$ contours), and the bottom row shows the standard deviation (with 0.2 contours)

larger covariance values result in smoother models and smaller covariance values result in rougher models. Choosing the best covariance is a trade-off between fitting the data well and creating a geologically plausible model without the resistivity being too 'patchy' or too smooth. Inversions with a standard uniform covariance (with the exception of ocean cells that are fixed) of 0.1, $0.2,0.3,0.4,0.5,0.75$ were tested (Table 2, Figs. 12 and 13).
The results of these test are outlined in Table 2. The best covariance value for a dataset is largely dependent on the model cell sizes, where this choice is dictated by the MT site spacing and complexity of the data (where closer site spacing and more complex data require smaller cell sizes). For the AusLAMP dataset with 55 $\mathrm{km}$ site spacing, large covariances $(>0.5)$ cause a substantially higher RMS. Whilst the model with a covariance of 0.2 has the lowest overall RMS and RMS per

Table 2 Results of covariance testing

\begin{tabular}{|c|c|c|c|c|c|c|}
\hline Cov & RMS & $\mathrm{RMS}_{\mathrm{var}}$ & KSU & No. of iterations & B/U RMS & $\begin{array}{l}\mathrm{B} / \mathrm{U} \text { no. } \\
\text { of iterations }\end{array}$ \\
\hline 0.1 & 2.17 & 14.9 & 4.9 & 137 & 1.6 & 194 \\
\hline 0.2 & 1.53 & 12.5 & 7.1 & 196 & 1.47 & 240 \\
\hline 0.2 smoothed once & 1.76 & 6.5 & 14.8 & 180 & 1.86 & 169 \\
\hline 0.3 & 1.6 & 9.7 & 6.9 & 192 & 1.61 & 167 \\
\hline 0.4 & 1.75 & 8.14 & 5.3 & 147 & 1.69 & 198 \\
\hline 0.5 & 1.97 & 8.0 & 5.8 & 162 & 1.83 & 180 \\
\hline 0.75 & 3.86 & 22.7 & 6.6 & 184 & 4 & 189 \\
\hline 0.4 to $10 \mathrm{~km}$ then 0.2 & 1.76 & 12.5 & 6.6 & 180 & 1.61 & 175 \\
\hline
\end{tabular}

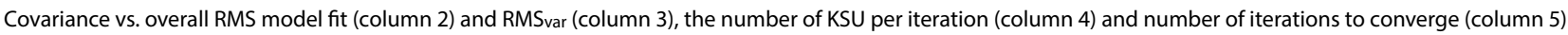
and the overall RMS misfit for the same model when the ocean is not locked (B/U= bathymetry unlocked, column 6$)$ and the number of iterations taken to converge when the ocean is not locked (column 7) 


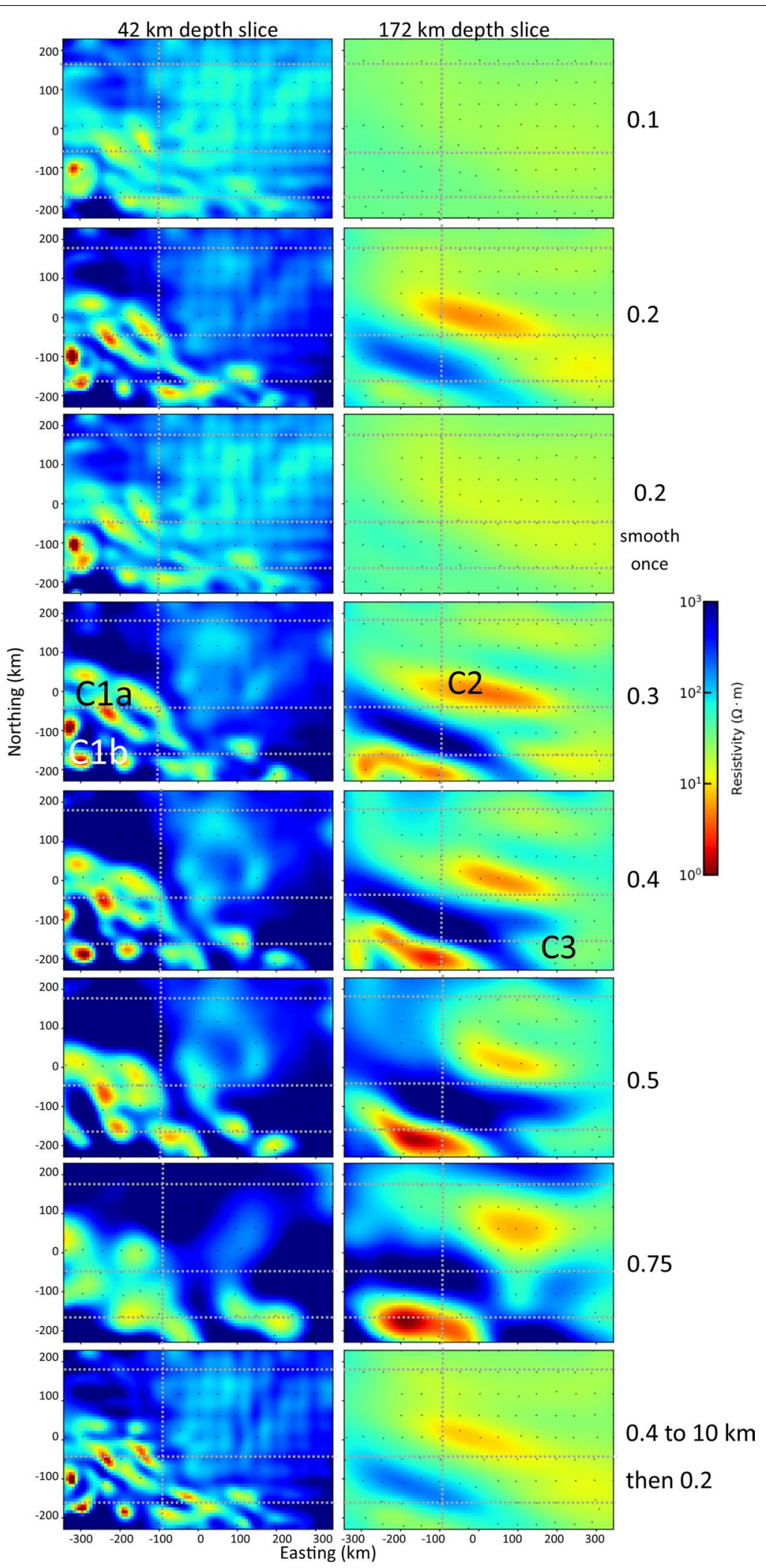

Fig. 12 Each row contains two electrical resistivity depth slices at 42 and $172 \mathrm{~km}$ for one covariance test. The eight rows correspond to the eight covariance tests mentioned including homogeneous covariance across the model of $0.1,0.2,0.3,0.4,0.5,0.75$ and 0.4 down to $10 \mathrm{~km}$ then 0.2 at greater depths. The grey dashed lines show the locations of the cross sections in Fig.13. The location of the MT sites inverted is shown by black dots 


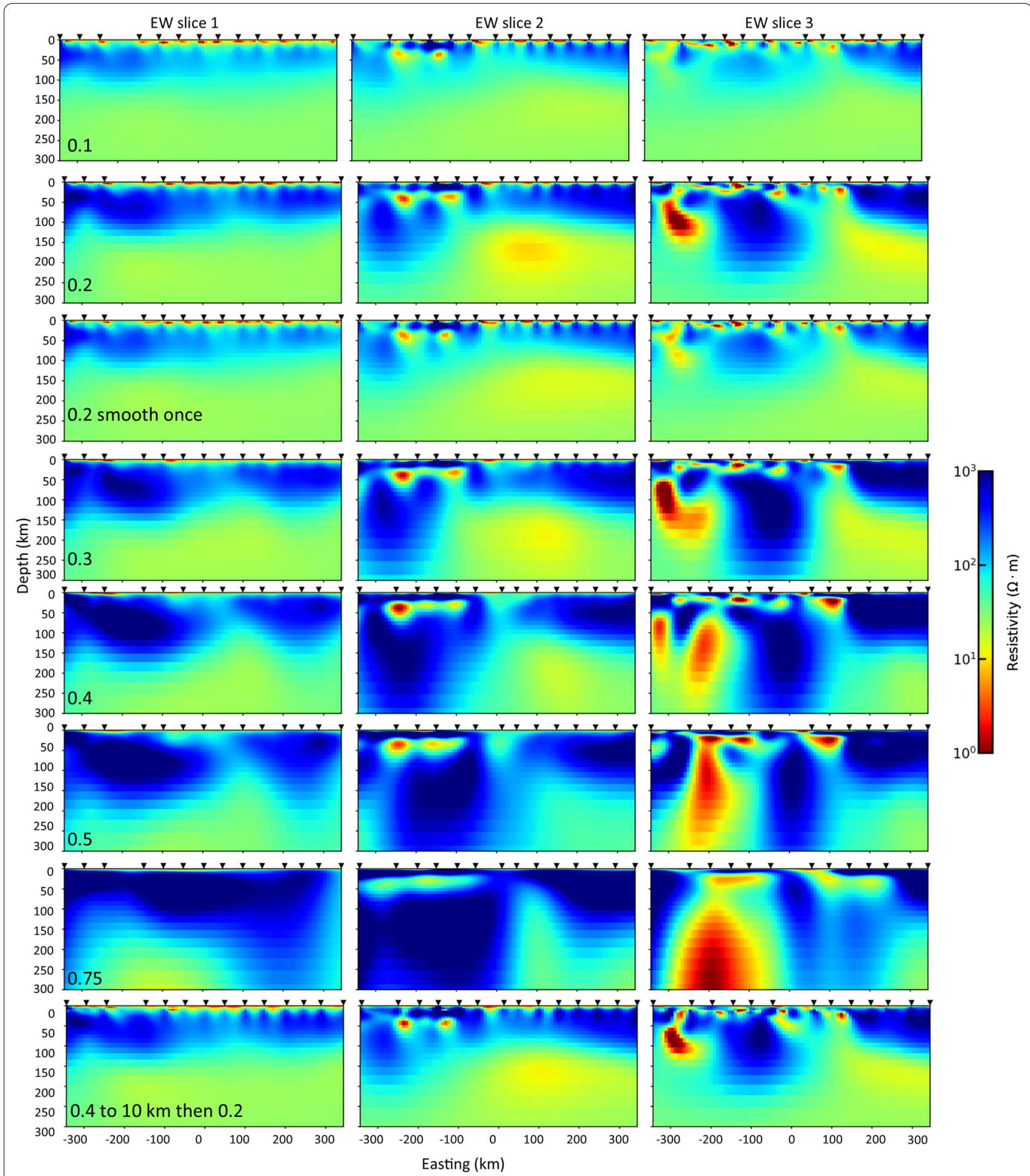

Fig. 13 East-west cross section through model to a depth of $300 \mathrm{~km}$ with covariance of $0.1,0.2,0.2$ with the smoothing applied once, $0.3,0.4,0.5$, 0.75 and 0.4 to $10 \mathrm{~km}$ then 0.2 beneath. The locations of these transects are shown in Fig. 12

decade (the averaged RMS of all sites in the inversion only for data in the period range of the specified decade; Table 2), the model has a very speckled appearance until a depth of about $35 \mathrm{~km}$. We tested a covariance of 0.4 for the top $10 \mathrm{~km}$, and 0.2 beneath to see whether this would encourage a closer fit of the data beneath 
$10 \mathrm{~km}$, and a smoother, less speckled model in the top $10 \mathrm{~km}$. Whilst there was not much improvement, this method may be useful, but more testing would need to be done to find the optimum depth to change covariance, or a gradual decrease in covariance with depth could be trialled, to reduce the distinct change that occurs at the transition from 0.4 to 0.2. Our approach is opposite to that preferred by Yang et al. (2015) with the Earthscope US Array data (site spacing $70 \mathrm{~km}$ ). They found that having a decreased covariance at depths shallower than $2 \mathrm{~km}$ gave them optimal results with a rougher shallow structure and a slightly smoother and simpler deep structure. The models with covariances of 0.5 or greater start to lose definition in the resistivity features and increase in RMS as covariance increases (Fig. 14). The models with a covariance value of 0.2 , 0.3 and 0.4 have better resolved features (less smooth). Whilst 0.2 has the lowest RMS, the model has a speckled appearance throughout the top $\sim 40 \mathrm{~km}$. The next lowest RMS, 0.3, has a speckled appearance down to $\sim 25 \mathrm{~km}$. Thus, 0.4 was chosen as the best covariance for this dataset due to the visual appearance and second lowest $\mathrm{RMS}_{\mathrm{var}}$, although the overall RMS (1.75) is 14\% larger than the minimum RMS for the 0.2 model (1.53).

All models in this study (except the one half-space inversion in Table 1) were tested with the ocean included and locked to a resistivity of $0.3 \Omega \mathrm{m}$ throughout the inversion. However for each of the covariances tested in Table 2, we also ran them with a starting/prior resistivity of $0.3 \Omega \mathrm{m}$, but the cells were not locked, for comparison. Columns 7 and 8 in Table 2 show the overall RMS and number of iterations taken to converge when the ocean cells are not locked. In most instances, the overall
RMS decreases, but the number of iterations to converge increases.

\section{Lateral cell size}

A choice of model cell size in the horizontal direction is a trade-off between computational time and having enough cells between each MT station to be able to incorporate interstation features. Whilst there is no hard and fast rule, a reasonable cell size seems to be about a fifth to a sixth of the spacing (Miensopust 2017, and references therein). The USArray has site spacing of $70 \mathrm{~km}$, with various modellers using a range of site spacing of $15 \mathrm{~km}$ (Bedrosian and Feucht 2014, cell size 21\% of site spacing), $10 \mathrm{~km}$ (Bedrosian 2016, 14\%) and $12.5 \mathrm{~km}$ (Meqbel et al. 2014, 18\% but also tested $25 \mathrm{~km}$; 35\%). AusLAMP has a smaller site spacing of approximately $55 \mathrm{~km}$, and Robertson et al. (2016) and Thiel et al. (2018) use a cell size of $10 \mathrm{~km}(18 \%)$. It is important to note the implicit relationship of the covariance with the number of cells (rather than physical cell size) in its implementation in ModEM3DMT. For example, if the same model covariance is applied to a 'delta function model' with a $1 \Omega \mathrm{m}$ cell in a $100 \Omega \mathrm{m}$ background, the resulting smoothed model will show this anomaly smoothed out across multiple cells. If the same covariance value is applied but the cell size is doubled, the 'smoothing distance' is also doubled.

Here, we test a lateral cell size of $5,7.5$ and $10 \mathrm{~km}$ (percentage of site spacing 9.1, 13.6 and $18.2 \%$, respectively). We first compare varying the cell size, and using the preferred covariance of 0.4 that was used for the $7.5 \mathrm{~km}$ cell size throughout all previous tests. It was found that the smaller the cell size the better the RMS (1.64 for $5 \mathrm{~km}$ vs. 1.99 for $10 \mathrm{~km}$; Table 3). However, the time taken for

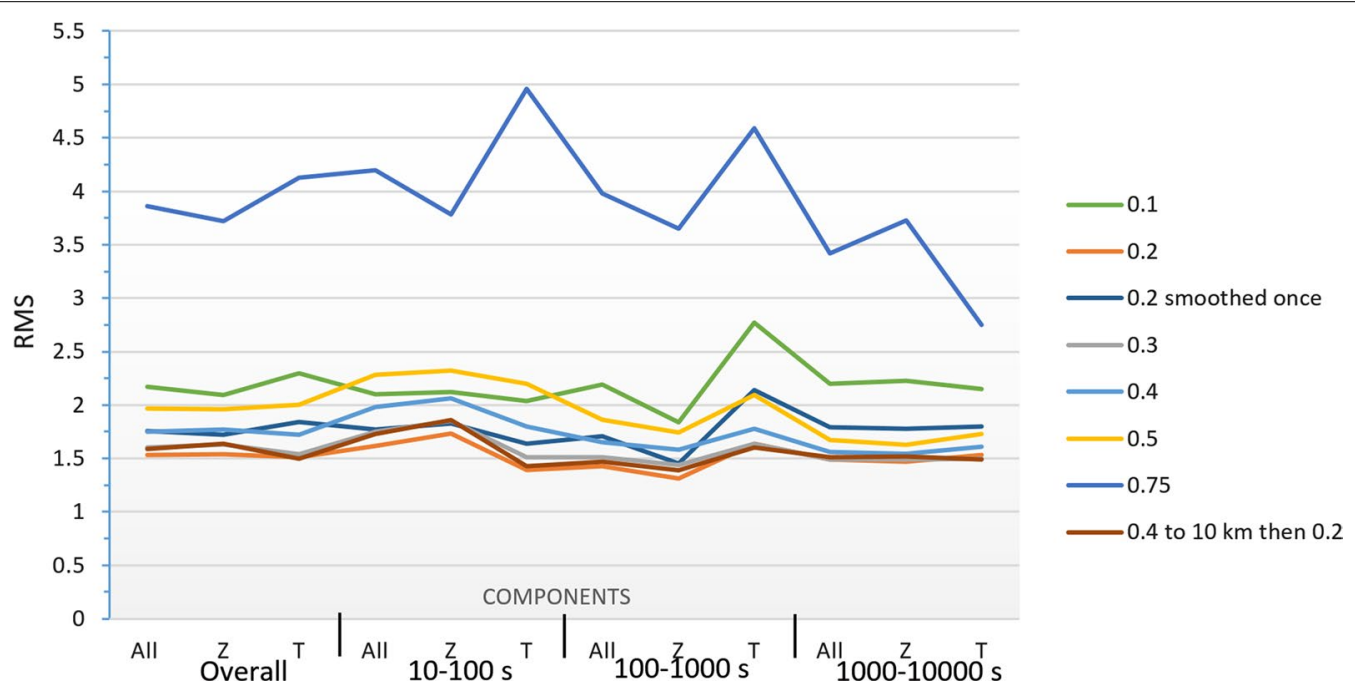

Fig. 14 Plot of covariance vs. RMS for the overall RMS, and for the period ranges of 10-100, 100-1000 and 1000-10,000 s 
Table 3 Results of lateral cell size tests

\begin{tabular}{|c|c|c|c|c|c|c|c|c|c|c|c|}
\hline Cell size (m) & Cov & $X$ & $Y$ & $X$ span $(\mathrm{km})$ & $Y$ span $(\mathrm{km})$ & RMS overall & RMS 10-100 s & $\begin{array}{l}\text { RMS 100- } \\
1000 \mathrm{~s}\end{array}$ & $\begin{array}{l}\text { RMS 1000- } \\
10,000 \mathrm{~s}\end{array}$ & $\mathrm{RMS}_{\mathrm{var}}$ & KSU \\
\hline 5000 & 0.5 & 102 & 156 & 3047 & 3317 & 2.03 & 2.2 & 1.95 & 1.9 & 7.7 & 8.4 \\
\hline 5000 & 0.4 & 102 & 156 & 3047 & 3317 & 1.64 & 1.79 & 1.56 & 1.55 & 10.0 & 9.8 \\
\hline 7500 & 0.4 & 68 & 104 & 3004 & 3274 & 1.75 & 1.98 & 1.65 & 1.56 & 8.1 & 5.3 \\
\hline 10,000 & 0.4 & 51 & 78 & 3318 & 3048 & 1.99 & 2.28 & 1.88 & 1.73 & 5.2 & 5.8 \\
\hline 10,000 & 0.3 & 51 & 78 & 3318 & 3048 & 1.54 & 1.8 & 1.4 & 1.32 & 9.1 & 5.3 \\
\hline
\end{tabular}

Details of the five inversions used to determine the best lateral cell size for AusLAMP inversion (5000, 7500 and 10,000 m)

These were run with all the same covariance (0.4) and then with a larger covariance for the $5 \mathrm{~km}$ to reduce speckling (0.5) and smaller for the $10 \mathrm{~km}$ to get a more detailed model (0.3). The starting RMS is constant, 25.3

the models to converge does not directly relate to the cell size. Whilst the $5 \mathrm{~km}$ cell size used $10 \mathrm{KSU}$ and the $10 \mathrm{~km}$ used $4.9 \mathrm{KSU}$, unexpectedly the $7.5 \mathrm{~km}$ cell size model used only $5.3 \mathrm{KSU}$.

To further test cell sizes though, the covariance needed to be adjusted to suit the different cell sizes, due to the application of the covariance in terms of cells and not distance. For a smaller cell size of $5 \mathrm{~km}$, a larger covariance of 0.5 was tested to reduce the speckled appearance of the model. This increased the RMS as expected, from 1.64 to 2.03 , but produced a smoother model. This also decreased the time taken, from 10 to $8.4 \mathrm{KSU}$. Deeper in the model (see $172 \mathrm{~km}$ depth slice; Fig. 15), the conductivity is more enhanced. (We have seen this earlier in covariance testing that a larger covariance introduced more conductive features at depth; Fig. 12.) Conversely, we tested the $10 \mathrm{~km}$ cell size model with a smaller covariance of 0.3 which resulted in a large decrease in RMS (1.54 for covariance 0.3 from 1.99 for covariance 0.4 ), and a small increase in the time taken (5.3 KSU up from 4.9 KSU). The lower covariance improved the model, helping to get more resolution from the larger cell size. With larger cell sizes, the deeper conductivity structures became more conductive. This model achieved the lowest overall RMS, but in comparison with the smaller cell size models, there appears to be less resolution at shallow depths. At mantle depths (see, for example, the 172 $\mathrm{km}$ depth slice, Fig. 15), conductive features similar to $\mathrm{C} 2$ and $\mathrm{C} 3$ observed in Fig. 9 are apparent. The resistivity structure appears to vary laterally more rapidly than the expected sensitivity of the MT data at those depths which may be a manifestation of anisotropy and similar features have observed in other global examples such as beneath the Arabian Shield (Bedrosian et al. 2019). Further testing such as synthetic modelling studies and investigation into the possibility of anisotropy are required to determine whether these features are indeed required by the data and/or anisotropic. Meqbel et al. (2014) found when testing 12.5 versus $25 \mathrm{~km}$ cell size for modelling the USArray
MT data that there was a significant increase in RMS for the larger cell size, and whilst the large-scale structures are relatively unchanged, conductors tend to be narrower and sometimes higher in amplitude for the smaller cell size. They note the biggest changes occur near the surface; however, deeper structures are also affected. Our results also show an increase in overall RMS with cell size that can be accounted for by decreasing the covariance for larger cell sizes. The computational time for an inversion is heavily dependent on the number of cells in the model; thus, it is favourable to have a larger cell size if the resultant model is comparable in resolution.

\section{Components to invert}

Within ModEM3DMT, there are various options for which data components to invert. Users of 3D codes commonly invert the full impedance tensor in conjunction with the tipper (e.g. Heise et al. 2013; Thiel and Heinson 2013; Robertson et al. 2016, 2017). In a 2D inversion, only the off-diagonal components, $Z x y$ and $Z y x$, are inverted, and the same can be done in a 3D inversion (e.g. Zhdanov 2010; Lindsey and Newman 2015). There are arguments for and against including the diagonal components such as that the diagonal components of the impedance tensor (which can be as little as 1/10th the magnitude of the off-diagonal component) can degrade the inversion due to lower signal-to-noise ratios (Newman et al. 2008), whereas others found that inverting the full impedance tensor provided a more detailed resistivity structure and revealed features that were otherwise missed by either 2D or 3D off-diagonal component inversions only (Tietze and Ritter 2013; Patro and Egbert 2011). If the tipper on its own is inverted, then the horizontal position and relative resistivity contrasts can be resolved, but the depth of features and absolute resistivity values cannot (e.g. Siripunvaraporn and Egbert 2009). To investigate the effects of inverting the different components, four inversions were run as outlined in Table 4, using a starting resistivity of $31 \Omega \mathrm{m}$, error floors of $7 \%$ of $\sqrt{|Z x y * Z y x|}$ for $Z x x$ and 


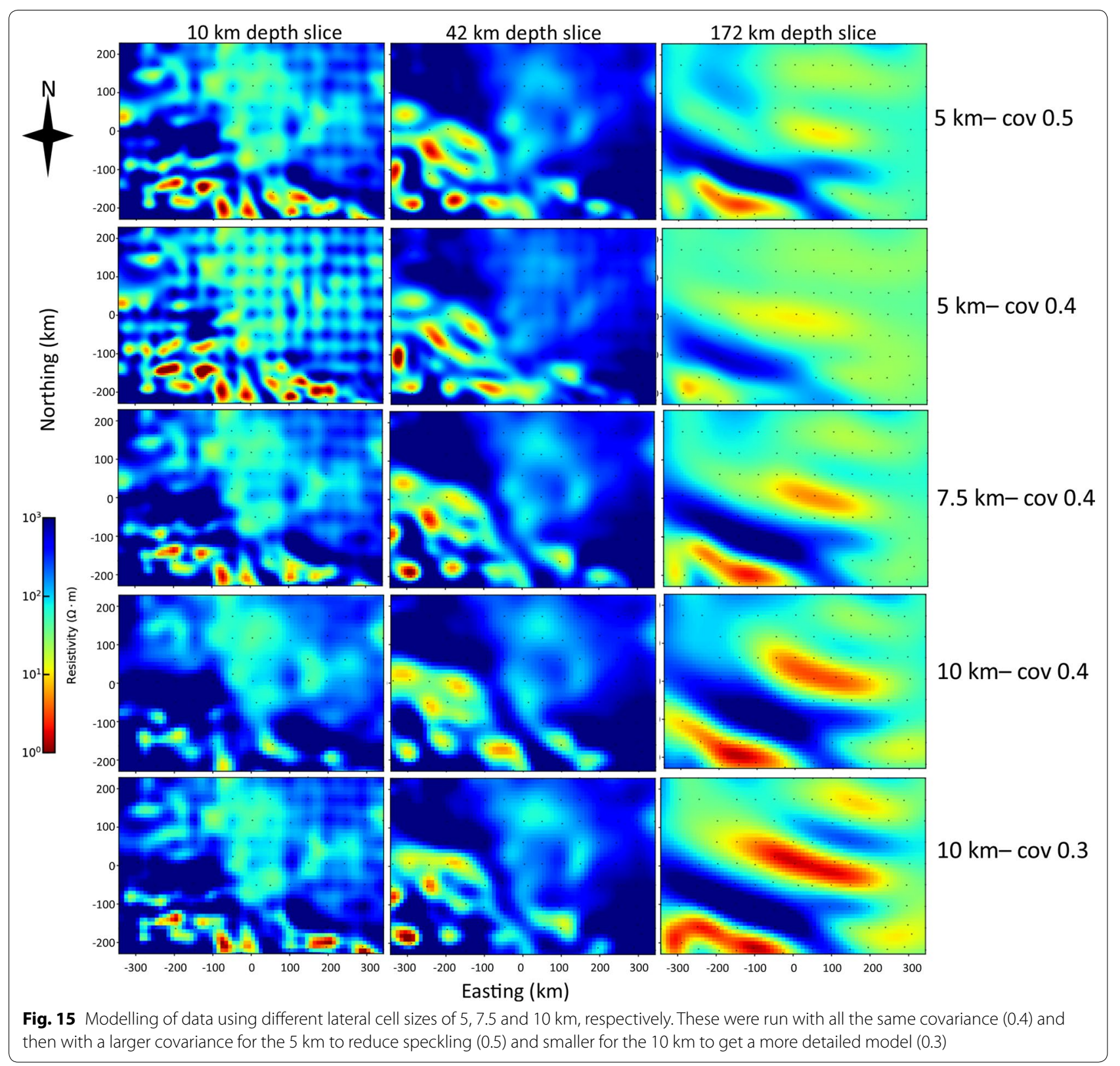

Table 4 Investigation of how inverting different components of the impedance tensor and tipper affects the final model

\begin{tabular}{|c|c|c|c|c|c|c|}
\hline Components inverted & Iterations & KSU & RMS inverted & RMS full $Z$ and $T$ & RMS full Z & RMS $T$ \\
\hline Full $Z$ and $T$ & 147 & 5.3 & 1.75 & 1.75 & 1.77 & 1.72 \\
\hline Tonly & 110 & 6.2 & 1.05 & 19.25 & 23.6 & 1.05 \\
\hline Full Z only & 4 & 171 & 1.58 & 5.89 & 1.58 & 9.91 \\
\hline$Z x y, Z y x$ only & 6.7 & 185 & 1.24 & 5.95 & 2.9 & 9.42 \\
\hline
\end{tabular}

The final RMS is given for the components that were inverted (column 3). The RMS is also given for a forward calculated model for the full impedance tensor and tipper, and the RMS for this overall (column 4) and the individual $Z$ (column 5) and $T$ (column 6) are also given

$Z y y, 3 \%$ of $\sqrt{|Z x y * Z y x|}$ for $Z x y$ and $Z y x$ and 0.01 for $T z x$ and Tzy. These results summarised in Table 4 show that when only data subsets are inverted, the resultant model does not fit the components that were not inverted, highlighting the importance of joint inversion of the various data components (full $Z$ and $T$ ). The results show that 
C1a is present to some degree in each of the data components (as visible in the $42 \mathrm{~km}$ depth slice of Fig. 16). The most conductive parts of $\mathrm{C} 2$ are from the tipper and the diagonal components of the impedance tensor, although all components show enhanced conductivity in the northeast of the model. An inversion of the tipper does not constrain depths or absolute resistivities well, and as such the $10 \mathrm{~km}$ depth slice is very conductive and appears more like the conductance (conductivity $\times$ distance) of the top $10 \mathrm{~km}$ rather than the conductivity at
$10 \mathrm{~km}$ (see bottom row in Fig. 16). These results highlight the importance of a full $Z$ and $T$ inversion and their respective contributions.

\section{Conclusions}

Whilst vast improvements have been made in recent years, 3D inversion of MT datasets is still very computationally expensive and takes a lot of time. As a result, it can be difficult to explore the impact that varying modelling parameters can have on the final model. The purpose

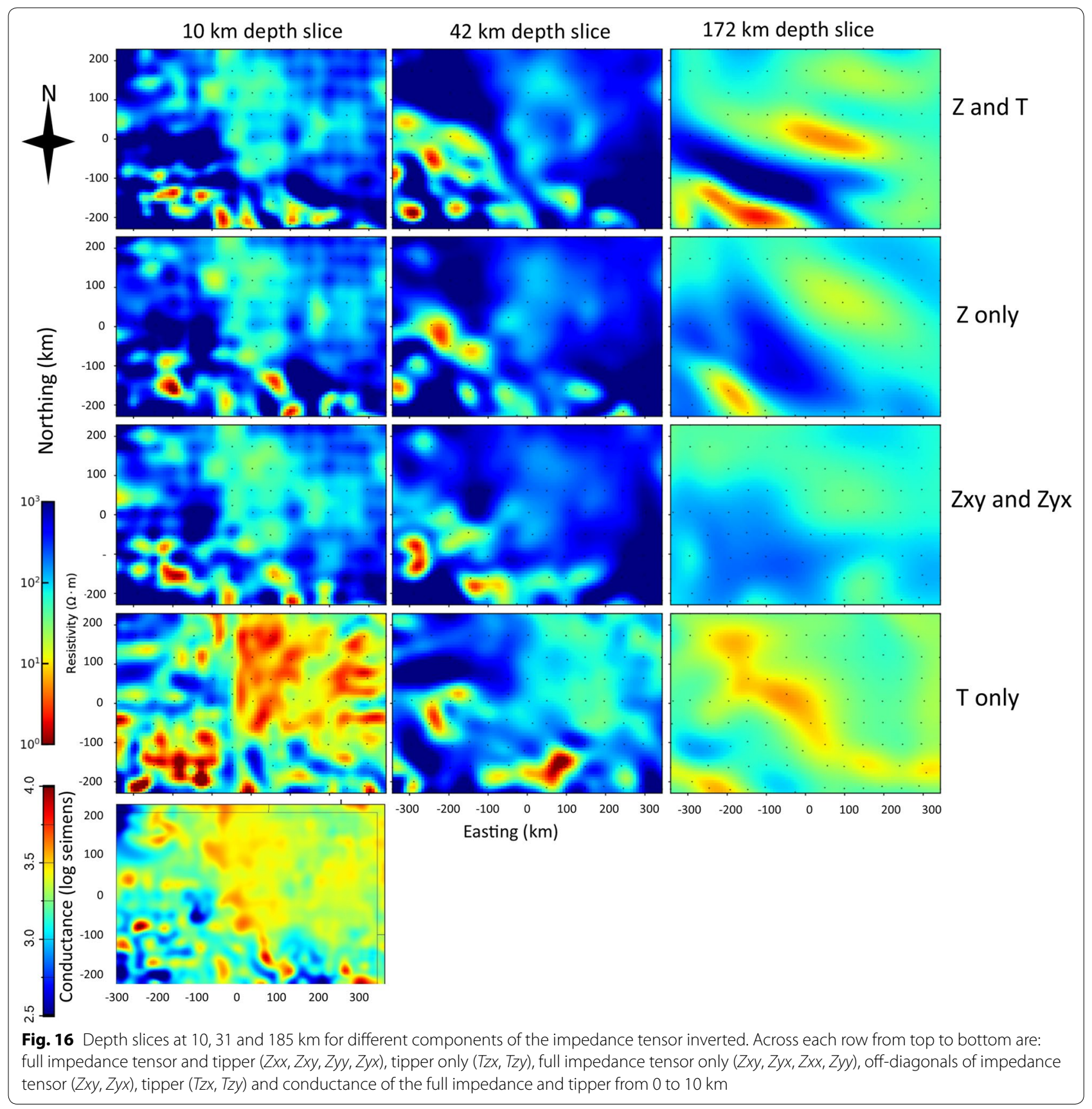


of our investigation using the ModEM3DMT inversion code was to determine the types of changes that can have significant impact on the resultant inversion, and which tests are required to help ensure robustness of the final model features, and guide the reader to more informed choice of model parameters. The AusLAMP dataset provides an ideal base for this testing. Whilst it is not our main intention to choose the best parameters for this dataset, we do conclude each section with our choice of preferred parameter/s, based on a combination of overall RMS, visual appearance and minimising the variance of the RMS across the period range and the different data components $(Z$ and $T)$, represented by a parameter we introduce, $\mathrm{RMS}_{\mathrm{var}}$.//

A reduction in the damping parameter, $\lambda$, from 1000 to 1 made little difference to the resultant model and the overall RMS. The greatest overall RMS of 1.98 was for the $\lambda$ of $10 . \lambda=1$ had the smallest overall RMS of 1.74 , but took 17 more iterations. Our preferred $\lambda$ starting value is $\lambda=1$; however, we performed subsequent testing using $\lambda=10$ to save computational time. Given the savings in computational time that the initial $\lambda$ value can provide, we suggest testing values early in the inversion process.

We investigated the effects of including prior knowledge in the starting/prior model. The inclusion of bathymetry and underlying ocean sediments required 10 less iterations than a half-space but a slightly higher RMS (1.98 instead of 1.82). The addition of conductive mantle of $10 \Omega \mathrm{m}$ beneath $410 \mathrm{~km}$ decreased the RMS slightly (to 1.81), but took an extra 30 iterations when compared to the model that only included bathymetry. When the prior model has the resistivity beneath $660 \mathrm{~km}$ reduced to $1 \Omega \mathrm{m}$, the final RMS is the lowest, 1.71 , taking one less iteration to converge than the model without the $660 \mathrm{~km}$ further reduction in resistivity. Our two preferred models were on both ends of the spectrum, a half-space, and the model that includes bathymetry and a $10 \Omega \mathrm{m}$ resistivity beneath $410 \mathrm{~km}$ depth and a $1 \Omega \mathrm{m}$ resistivity beneath 660 $\mathrm{km}$ (i.e. all prior information is included). However, our model area is several hundred kilometres from the ocean, so it is probably unlikely that a survey area closer to the ocean would find a half-space without ocean information included to be the preferred model.

The dependence of the final inverted model on the prior/starting model was further tested by trialling seven different half-space prior models between 3 and 1000 $\Omega \mathrm{m}$, including one inversion with prior/starting resistivity of $69 \Omega \mathrm{m}$, which was the averaged apparent resistivity across all sites and all data periods. It was found that the inverted models generally showed the same features but at different absolute resistivities, thus highlighting the importance of using a suitable starting model. The robustness of features was also assessed by deriving the standard deviation across the converged models of these seven half-space priors. We found that using the averaged apparent resistivity across all data points for the prior/starting resistivity was a suitable starting point and resistivity values close to this could be tested. Our preferred model used a prior resistivity of $31 \Omega \mathrm{m}$ which had the second best overall RMS and took the least number of iterations.

Similarly, a good choice in the covariance smoothing parameter is also important and is dependent on the site spacing, cell size and complexity of the resistivity structure. For the site layout ( $55 \mathrm{~km}$ spaced array) and cell size used here $(7.5 \mathrm{~km})$, a covariance of 0.4 was most suitable as this reduced spotting in shallower depth slices that would arise with smaller covariances and prevented the dramatic over-smoothing of higher covariances. Given a smaller cell size, a higher covariance is required which can be seen in the depth slices of the $5 \mathrm{~km}$ cell size model of Fig. 12, where the resistivity is spotty. This is due to the current formulation of covariance in terms of cells and not distance. When the covariance for the $5 \mathrm{~km}$ cell size model is increased from 0.4 to 0.5 , the model looks more geologically plausible and smoother and is a better choice. Similarly, when the cell size is increased to $10 \mathrm{~km}$, a covariance of 0.3 was preferred.

We inverted data subsets individually in the last section (full $Z$ and $T, Z$ only, $T$ only, $Z x y, Z y x$ only) and found that it is best to include all of the information (i.e. full $Z$ and $T$ inversion) as inversion of subsets fails to explain the other data components not included in the inversion.

With the advance and parallelisation of 3D inversion software and more readily available high-performance computing facilities, it is now possible to invert large datasets with hundreds of sites across several $1000 \mathrm{~km}$. However, the entire AusLAMP set (and the USArray) will include thousands of MT sites and a task for the future is to consider how these will be inverted to obtain a suitable model of the resistivity of the Australian (or US) lithosphere within a feasible amount of time and within the limits of computing facilities. For example, the desired output of AusLAMP is to image the resistivity structure of the entire lithosphere beneath Australia with approximately 3200 sites and 7.7 million $\mathrm{km}^{2}$ in area, but for now outputs are centred on the modelling of smaller regions. But whether it be the smaller regions we currently manage, or whole continent inversions, and whether AusLAMP or another large-scale array, this information should serve to focus the inversions and parameter testing required and reduce the time and computational demand. 


\section{Acknowledgements}

All inversions were performed using Raijin from the National Computational Infrastructure in Canberra, Australia provided by the Australian Government under the National Computational Merit Allocation Scheme. Data were collected by Philippa Mawby, Geoffrey Axford and Bruce Goleby. The MT instruments used were from the AuScope instrumentation pool. Naser Meqbel developed the software 3Dgrid that was used for generating modelling inputs and viewing some outputs. Most plots were produced using the open-source MT software MTpy (Krieger and Peacock 2014; Kirkby et al. 2019). K. Robertson and S. Thiel publish with the permission of the Director of the Geological Survey of South Australia.

\section{Authors' contributions}

KR was involved in data acquisition, processing, modelling and writing the text. ST was involved in data processing and generating ideas for modelling and editing the manuscript. NM provided technical advice regarding the ModEM3DMT inversion code and developed the software 3Dgrid that was used for generating modelling inputs and viewing outputs and edited the manuscript. All authors read and approved the final manuscript.

\section{Funding}

Funding for data acquisition was from Geological Survey of South Australia's PACE Copper Initiative.

\section{Availability of data}

The magnetotelluric data used in this manuscript can be downloaded in EDI format from the South Australian Resources Information Gateway (SARIG) https://map.sarig.sa.gov.au/Shortcut/MTInterpreted.

\section{Competing interests}

The authors declare that they have no competing interests.

\section{Author details}

${ }^{1}$ Department for Energy and Mining, Geological Survey of South Australia, Adelaide, Australia. ${ }^{2}$ School of Physical Sciences, University of Adelaide, Adelaide, Australia. ${ }^{3}$ The Helmholtz Centre Potsdam-GFZ German Research Centre for Geosciences, Potsdam, Germany. ${ }^{4}$ Present Address: National Observatory of Brazil, Rio de Janeiro, Brazil.

Received: 5 August 2019 Accepted: 18 December 2019 Published online: 07 January 2020

\section{References}

Bedrosian PA (2016) Making it and breaking it in the midwest: continental assembly and rifting from modeling of earthscope magnetotelluric data. Precambr Res 278:337-361

Bedrosian PA, Feucht DW (2014) Structure and tectonics of the northwestern United States from Earthscope USArray magnetotelluric data. Earth Planet Sci Lett 402:275-289

Bedrosian PA, Peacock JR, Dhary M, Sharif A, Feucht DW, Zahran H (2019) Crustal magmatism and anisotropy beneath the Arabian shield-a cautionary tale. J Geophys Res Solid Earth 124(10):10153-10179

Cerv V, Menvielle M, Pek J (2007) Stochastic interpretation of magnetotelluric data, comparison of methods. Ann Geophys. https://doi.org/10.4401/ ag-3084

Chave A, Thomson D (2004) Bounded influence magnetotelluric response function estimation. Geophys J Int 157(3):988-1006

Chen J, Hoversten GM, Key K, Nordquist G, Cumming W (2012) Stochastic inversion of magnetotelluric data using a sharp boundary parameterization and application to a geothermal site. Geophysics 77(4):E265-E279

Constable S (2015) Geomagnetic induction studies, vol 5, 2nd edn. Elsevier, Oxford, pp 219-254

Didana YL, Heinson G, Thiel S, Krieger L (2017) Magnetotelluric monitoring of permeability enhancement at enhanced geothermal system project. Geothermics 66:23-38

Egbert GD, Kelbert A (2012) Computational recipes for electromagnetic inverse problems. Geophys J Int 189:251-267

Gamble TD, Goubau WM, Clarke J (1979) Error analysis for remote reference magnetotellurics. Geophysics 44(5):959-968
Heise W, Caldwell TG, Bertrand EA, Hill GJ, Bennie SL, Ogawa Y (2013) Changes in electrical resistivity track changes in tectonic plate coupling. Geophys Res Lett 40(19):5029-5033

Huang X, Xu Y, Karato S-I (2005) Water content in the transition zone from electrical conductivity of wadsleyite and ringwoodite. Nature 434:746

Ishii T, Huang R, Fei H, Koemets I, Liu Z, Maeda F, Yuan L, Wang L, Druzhbin D, Yamamoto T, Bhat S, Farla R, Kawazoe T, Tsujino N, Kulik E, Higo Y, Tange Y, Katsura T (2018) Complete agreement of the post-spinel transition with the 660-km seismic discontinuity. Sci Rep 8(1):6358

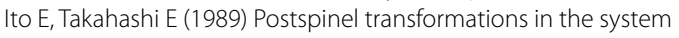
$\mathrm{Mg}_{2} \mathrm{SiO}_{4}-\mathrm{Fe}_{2} \mathrm{SiO}_{4}$ and some geophysical implications. J Geophys Res Solid Earth 94(B8):10637-10646

Kelbert A, Egbert GD, deGroot Hedlin C (2012) Crust and upper mantle electrical conductivity beneath the yellowstone hotspot track. Geology 40(5):447

Kelbert A, Meqbel N, Egbert G, Tandon K (2014) ModEM: a modular system for inversion of electromagnetic geophysical data. Computat Geosci 66:40-53

Kennett BLN, Salmon M, Saygin E, Group AW (2011) AusMoho: the variation of Moho depth in Australia. Geophys J Int 187(2):946-958

Kirkby A, Zhang F, Peacock J, Hassan R, Duan J (2019) The MTPy software package for magnetotelluric data analysis and visualisation. J Open Source Softw 4:1358

Krieger L, Peacock J (2014) MTpy: a Python toolbox for magnetotellurics. Comput Geosci 72:167-175

Lindsey NJ, Newman GA (2015) Improved workflow for 3D inverse modeling of magnetotelluric data: examples from five geothermal systems. Geothermics 53:527-532

Meqbel NM, Egbert GD, Wannamaker PE, Kelbert A, Schultz A (2014) Deep electrical resistivity structure of the Northwestern US derived from 3-D inversion of usarray magnetotelluric data. Earth Planet Sci Lett 402:290-304 (Special issue on USArray science)

Meqbel N, Weckmann U, Muoz G, Ritter O (2016) Crustal metamorphic fluid flux beneath the Dead Sea Basin: constraints from 2-D and 3-D magnetotelluric modelling. Geophys J Int 207(3):1609-1629

Miensopust MP (2017) Application of 3-D electromagnetic inversion in practice: challenges, pitfalls and solution approaches. Surv Geophys 38(5):869-933

Muñoz G, Rath V (2006) Beyond smooth inversion: the use of nullspace projection for the exploration of non-uniqueness in MT. Geophys J Int 164(2):301-311

Newman GA, Gasperikova E, Hoversten GM, Wannamaker PE (2008) Threedimensional magnetotelluric characterization of the Coso geothermal field. Geothermics 37(4):369-399

Parkinson WD, Jones FW (1979) The geomagnetic coast effect. Revi Geophys 17(8):1999-2015

Patro PK, Egbert GD (2011) Application of 3D inversion to magnetotelluric profile data from the Deccan Volcanic Province of Western India. Phys Earth Planet Inter 187(1):33-46

Robertson K, Heinson G, Thiel S (2016) Lithospheric reworking at the Proterozoic-Phanerozoic transition of Australia imaged using AusLAMP magnetotelluric data. Earth Planet Sci Lett 452:27-35

Robertson KE, Heinson GS, Taylor DH, Thiel S (2017) The lithospheric transition between the Delamerian and Lachlan orogens in Western Victoria: new insights from 3D magnetotelluric imaging. Aust J Earth Sci 64(3):385-399

Shearer PM, Flanagan MP (1999) Seismic velocity and density jumps across the 410- and 660-kilometer discontinuities. Science 285(5433):1545-1548

Siripunvaraporn W, Egbert G (2009) WSINV3DMT: vertical magnetic field transfer function inversion and parallel implementation. Phys Earth Planet Inter 173(3):317-329

Slezak K, Jozwiak W, Nowozynski K, Orynski S, Brasse H (2019) 3-D studies of mt data in the Central Polish Basin: influence of inversion parameters, model space and transfer function selection. J Appl Geophys 161:26-36

Thiel S, Heinson G (2013) Electrical conductors in Archean mantle-result of plume interaction? Geophys Res Lett 40(12):2947-2952

Thiel S, Reid A, Heinson G, Robertson K (2018) Mapping and characterizing lithosphere discontinuities: examples of southern Australia using AusLAMP MT. In: Proceedings of the 24th electromagnetic induction workshop, At Helsingor, Denmark 
Tietze K, Ritter O (2013) Three-dimensional magnetotelluric inversion in practice-the electrical conductivity structure of the San Andreas fault in Central California. Geophys J Int 195(1):130-147

Xu Y, Shankland T, Poe B (2000) Laboratory-based electrical conductivity in the Earth's mantle. J Geophys Res Solid Earth 105(B12):27865-27875

Yang B, Egbert GD, Kelbert A, Meqbel NM (2015) Three-dimensional electrical resistivity of the North-Central USA from EarthScope long period magnetotelluric data. Earth Planet Sci Lett 422:87-93

Yoshino T, Nishi M, Matsuzaki T, Yamazaki D, Katsura T (2008) Electrical conductivity of majorite garnet and its implications for electrical structure in the mantle transition zone. Phys Earth Planet Inter 170(3-4):193-200
Zhdanov MS (2010) Electromagnetic geophysics: notes from the past and the road ahead. Geophysics 75(5):75A49-75A66

\section{Publisher's Note}

Springer Nature remains neutral with regard to jurisdictional claims in published maps and institutional affiliations.

\section{Submit your manuscript to a SpringerOpen ${ }^{\circ}$ journal and benefit from:}

- Convenient online submission

- Rigorous peer review

- Open access: articles freely available online

- High visibility within the field

- Retaining the copyright to your article

Submit your next manuscript at $\boldsymbol{\nabla}$ springeropen.com 